\title{
La viruela y las políticas de inmunización en Argentina en el largo plazo
}

\author{
Maria Silvia Di Liscia*
}

\section{RESUMEN}

La historia de la viruela en Argentina, peligrosa enfermedad infecciosa y epidémica, se estudia a través de las diversas políticas públicas desde el siglo XIX al XX. Se enlaza a la enfermedad y a su principal terapia, la vacuna, que involucra las prácticas médicas y el derecho al uso individual del cuerpo, frente al significado social y colectivo inmerso en la inmunización universal. También se analiza la relación entre los gobiernos de diverso signo político y la comunidad internacional frente a la producción de vacunas y las campañas de vacunación desde su implementación hasta la erradicación de la enfermedad.

Palabras clave: Argentina; viruela; vacunación; inmunización.

\section{A varíola e políticas de imunização na Argentina a longo prazo}

\section{RESUMO}

A história da varíola na Argentina, perigosa doença infecciosa e epidêmica, é estudada por meio das diversas políticas públicas do século XIX ao XX. Está ligada à doença e à sua principal terapia, a vacina, que envolve as práticas médicas e o direito ao uso individual do corpo, contra o significado social e coletivo imerso na imunização universal. Também é analisada a relação entre governos de diversas formaçôes políticas e a comunidade internacional no que diz respeito à produção de vacinas e campanhas de vacinação desde sua implantação até a erradicação da doença.

Palavras-chave: Argentina; varíola; vacinação; imunização. 


\title{
Smallpox and immunization policies in Argentina in the long term
}

\begin{abstract}
This article examines the history of smallpox, a dangerous infectious and epidemic disease, in Argentina through the government's various public health policies from the 19th to the 20th century. The article discusses both the disease and the main tool used to fight it, vaccination, which involves medical practices as well as the debate between the right to individual use of the body and the social and collective responsibilities of universal immunization. The article also analyzes the relationship between governments of diverse political backgrounds and the international community regarding the production of vaccines and vaccination campaigns from their implantation to the eradication of the disease.
\end{abstract}

Keywords: Argentina; smallpox; vaccination; immunization.

\section{Introducción}

La viruela, causada por el Virus Variola Major, es la única enfermedad erradicada en el mundo. Tal situación se denota como un éxito de colaboración y coordinación entre organismos internacionales (la Organización Mundial de la Salud, en adelante OMS; la Organización Panamericana de la Salud, en adelante: OPS-PAHO) y los Estados nación participantes. Se trata de una temática analizada laudatoriamente desde esos organismos oficiales (RODRIGUES, 1975; L'ERADICATION; 1980, SMALL Pox is dead!, 1980; FENNER; HENDERSON; ARITA; JEZEK; LADNYI, 1988) y de manera crítica por una copiosa y reciente literatura (CUETO; PALMER, 2015; BIRN, 2016; PORRAS GALLO; BALLESTER AÑÓN, 2016; HOLMBERG; BLUME; GREENOUGH, 2017). Argentina está presente en relación al conjunto de países de la región, demostrándose en general el acompañamiento a esta medida publicitada como un suceso de la técnica médica occidental, a través de la expansión de campañas intensivas de vacunación y de un sistema posterior de vigilancia epidemiológico.

En este trabajo, se profundiza sobre la experiencia y práctica de la vacunación antivariólica en Argentina en una "larga duración", en relación a su constitución sobre política pública pero también como asunto tecnológico que involucra, entre otras cuestiones, a las comunidades médicas. Para ello, se parte de las consideraciones generales sobre la inoculación y variolización hasta el establecimiento de la vacunación hasta los considerables esfuerzos de expandir esta práctica en las campańas de finales del S. XX. Se trata de un ejercicio de historia tanto local-nacional como global, ya que pivota entre las consideraciones de la periferia científica a las decisiones tomadas más allá de las fronteras nacionales y que incidieron en las políticas 
públicas del país ${ }^{1}$. En aportes anteriores se avanzó sobre la aparición de la viruela en suelo argentino, sobre sus efectos en la población nativa y la obligatoriedad de la medida, además de las campañas del inicio del siglo XX (DI LISCIA, 2011; 2017).

Este ejercicio histórico permite observar de cerca la viruela y su preventivo, la vacuna, como objetivos privilegiados de análisis, sin desconocer el correlato general sobre la higiene y sanidad ni las posturas de sus líderes y enunciadores, así como su relación con la conformación y funciones de los agencias. Desde finales del Siglo XVIII hasta finales del XX, nuestro desafío es prestar atención a la dupla enfermedad-inmunidad, que se transforman al mismo tiempo que la sociedad en su conjunto. En este camino, el territorio que luego se denominaría República Argentina (Argentina a secas en este texto), sufrió significativas transformaciones ya que pasó de ser un área dependiente de una metrópoli a desarrollar sus propias formas de gobierno, con las dificultades consiguientes, para establecer un Estado en expansión económica bajo un régimen conservador a nivel político. En un convulso Siglo XX, ascendieron al escenario otros actores que llegaron al poder bajo partidos de masas (radicales y justicialistas), con la impronta de un modelo socioeconómico de carácter industrialista e interventor. También irrumpieron las decisiones populares diversos golpes de Estado que coartaron y reprimieron las decisiones mayoritarias, bajo la égida militar y empresarial autoritaria. En ese trayecto se sucedieron importantes transformaciones demográficas. La esperanza de vida al nacer aumentó de 33 a 75 años entre 1869 y 2010. Descendió la tasa de mortalidad ${ }^{2}$. El analfabetismo también descendió, al compás la obligatoriedad de la escolaridad primaria establecida en 1884: en 1869 era de $71,4 \%$ y en 2001 , era de 2,6 \% (TEDESCO; CARDINI, 2007, p. 462).

El caso argentino resulta entonces interesante para analizar cómo se estableció la vacunación para el control de una enfermedad grave y de qué manera el proyecto se unió a los afanes internos de las élites médicas en conexión con el Estado en diferentes niveles y a las decisiones de organismos internacionales. Se toman en cuenta los puntos refractarios a las prácticas de inoculación variólica y luego de vacunación, producto tanto de resistencias a posibles accidentes como al avance sobre la privacidad, en esa compleja tensión entre intereses del individuo y ventajas del colectivo que refieren a la inmunidad y el contagio de enfermedades (MOULIN, 1999). No es posible descartar el aspecto estético de la enfermedad dada la desfiguración que acarreaba a los supervivientes. Las pústulas signo del virus eran temidas y por eso los médicos hablaban de la viruela como una de las dolencias "más feas y repugnantes" (CONI, 1917, p. 629).

Las vacunas, eje de este trabajo, están vinculadas con estrategias estatales de investigación, producción y difusión, tanto del producto como del mensaje higiénico de inmunidad a la

\footnotetext{
${ }^{1}$ Sobre epidemiología, América Latina e historia global, ver Espinosa (2013), Webb (2020) y Birn (2020).

${ }^{2}$ La Tasa Bruta de Mortalidad era entre 1870-1875 de 31,9/1000; entre 1895/1899 de 28,9/1000; entre 1920-1925 de 15,1/1000; entre 1940-1945 de 11,3/1000; entre 1960-1965 de 8,8/1000 y entre 1980-1985, de 8,5/1000 (GRUSHKA, 2014, p. 109).
} 
población que está inserto en la educación. Este aspecto ha sido analizado en otras naciones latinoamericanas y se vincula a la extensión masiva de las medidas de vacunación ${ }^{3}$. Finalmente, se consideran los aspectos sanitario-políticos involucrados en la erradicación, a partir de las resoluciones de la OMS-OPS de 1958 en adelante. Bhattacharya y Ávila Pereira Campani (2019) indican que un examen de las campañas internacionales revela el protagonismo de otros actores y la voluntad de negociación de una amplia gama de naciones en igualdad de condiciones. En el caso particular de Argentina, estos aspectos aportan a las problemáticas de análisis global sobre la circulación de epidemias, los saberes, las comunidades médicas y científicas y las medidas de control sanitario.

Las fuentes utilizadas, éditas e inéditas, provienen de Tesis médicas, manuales y publicaciones del Departamento Nacional de Higiene (DNH) y de otras revistas oficiales, como las del Consejo Nacional de Educación. También se consultó el repositorio digital de la Organización Panamericana de la Salud (OPS) y la Organización Mundial de la Salud (OMS) entre 1920-1988 y prensa en general, sobre todo las campañas de vacunación de dos Provincias, Santa Fé y La Pampa

\section{Inoculación y variolización: desajustes y encuentros}

Las pandemias de viruela aparecieron en América a raíz de la invasión europea, y aunque es difícil calibrar demográficamente su letalidad, indudablemente incidieron en el control occidental sobre las etnias originarias tanto por tratarse de una enfermedad extraña, con alto contagio, como por su directa vinculación con los grupos finalmente vencedores. La literatura al respecto ha demarcado la intensa relación entre epidemias y avance capitalista en todo el mundo (McNEILL, 1976; WATTS, 1999; RILEY, 2010). En relación a la viruela, no se conocía ningún paliativo y además de víctimas mortales, luego de las epidemias, quedaban personas con marcas permanentes en la piel y a veces, también ciegas.

\footnotetext{
${ }^{3}$ Sobre México, ver Carrillo (2017); en relación a Brasil, Hochman (2011), Benchimol (2017) y Cueto y Palmer (2015).

${ }^{4}$ La provincia de Santa Fé era la tercera más poblada en el período analizado y forma parte del grupo de provincias históricas (entre las que se cuenta a Buenos Aires, Córdoba, Mendoza, San Juan, Catamarca, La Rioja, San Luis, Salta, Jujuy, Catamarca, Santiago del Estero, Corrientes, Entre Ríos y Tucumán), organizadas antes de 1884. En 1884 se organizaron los Territorios Nacionales sobre tierras que se habían mantenido bajo el control de las etnias indígenas, luego de cruentas campańas militares. Estos Territorios se denominaron Territorio Nacional de La Pampa, Neuquén, Río Negro, Chubut, Santa Cruz, Tierra del Fuego, de los Andes, de Misiones, Chaco y Formosa y se provincializaron a lo largo de la segunda mitad del Siglo XX. La Pampa se pobló con migrantes de otras provincias y del exterior y sufrió una importante pérdida demográfica a raíz de la crisis agroclimática y económica de mediados de 1930. En 1952 se constituyó como una de las provincias nuevas. La elección de ambas jurisdicciones obedece al análisis de las estrategias en campañas de vacunación de diferentes áreas a nivel demográfico e histórico (una síntesis en DI LISCIA, 2017).
} 
A finales del Siglo XVIII, el actual territorio argentino se encontraba bajo la egida colonial y desde entonces se citan ejemplos tempranos de uso de la inoculación, práctica muy antigua para lograr la inmunidad introduciendo en el cuerpo de una persona no infectada el virus "humanizado" para promover una enfermedad menos grave que la original'.

Las experiencias realizadas por Edward Jenner sobre el Cow Pox - virus vacuno similar a la viruela - son muy conocidas para volverlas a relatar así como su despliegue al resto de Europa y a América, a través de la Expedición Balmis entre 1803-1804. Ese esfuerzo se inscribe como un capítulo ascendente de la historia del control de la enfermedad, pero alimentó un proceso vinculado pero no similar al de la vacunación al menos en sus antecedentes locales. Otras personas, no necesariamente médicos, utilizaron similares metodologías para llegar con el virus "humanizado" como un empresario portugués quien arribó al Río de La Plata con cuatro esclavas en 1805, a partir de las cuales se inmunizaron varios cientos (DIAZ, 1876). En 1810 las entonces colonias se independizaron de España en un proceso difícil y complejo, que implicó inicialmente la fragmentación del territorio y las pugnas entre diferentes sectores para hacerse con la centralidad del poder.

Una de las escasas medidas sanitarias en esos tiempos difíciles fueron las inoculaciones del denominado "beneficio vaccínico". Se realizaba en el brazo, de persona a persona, aunque en el caso de las mujeres, los médicos, tal y como asegura una tesis doctoral de de entonces, recomendaban vacunar en los muslos para evitar las feas cicatrices que podían afear al "bello sexo" y por lo tanto ser causa de reluctancia (BARÓN DE FINCK, 1855). En dicho texto, se indicaba que dicha cuestión era debido al posible contagio de infecciones y enfermedades peligrosas de quien había tenido el virus, además por supuesto de ocasionar la viruela (BARÓN DE FINCK, 1855). Como hemos indicado, siguió siendo una medida resistida que requería considerable esfuerzo público (DI LISCIA, 2011).

El Estado argentino se reorganizó en la segunda mitad del Siglo XIX y al mismo tiempo, se desenvolvió un sector de profesionales médicos que presionó para aplicar al campo de la salud las teorías microbiológicas y se insertó en diferentes estratos del sistema público, promoviendo una notable renovación institucional. Las epidemias de viruela se presentaban periódicamente en todo el territorio, incluso entre los pueblos indígenas donde la letalidad era muy alta, en el orden del $30 \%$ de los infectados sobre todo con la variante más grave (DI LISCIA, 2011).

La viruela aumentó significativamente en las áreas urbanas y rurales en la segunda mitad del XIX. Entre 1855-57, hubo 25 decesos por esta causa en la ciudad de Buenos

\footnotetext{
${ }^{5}$ L'ERADICATION Mondiale de la Variole. Rapport final de la Comission Mondiale pour la Certification de la Eradication de la Variole. Genève: OMS, 1980. Se reconocen diversos tipos de viruela; durante gran parte del S. XIX se discriminaba en dos: viruela discreta o menor, que ocasionaba una infección leve y viruela confluente/hemorrágica o mayor, con menores positividades de supervivencia y mayores efectos secundarios. En el S. XX se discriminaba entre viruela mayor y alastrín, considerando la segunda con un carácter menos virulento que la primera.
} 
Aires y 35 en la campańa; entre 1858-1867, ascendieron a 666 en la ciudad y a 1.728 en la campańa y en el decenio 1868-1877, a 4.796 y 9.875 respectivamente. Los picos epidémicos con miles de afectados y una alta mortalidad se produjeron en 1871, 1875 y 1876 (CONI, 1878). Tal situación debe verse en paralelo con las modificaciones demográficas y su impacto urbano. En 1869 había en el país 1.830.214 habitantes, concentrados sobre todo en la región pampeana y metropolitana, aunque el Noroeste seguía siendo aún una de las regiones más pobladas. La inmigración comenzaba a imponerse, puesto que en ese total había 211.000 extranjeros. Por entonces, Buenos Aires tenía 177.000 habitantes, mientras que Córdoba y Santa Fé, las ciudades que le seguían directamente en el número de habitantes, unos 20.000. En 1881, la recientemente incorporada Capital de la nación tenía ya 289.925 habitantes y sólo en la provincia de Buenos Aires la población alcanzaba a 526.584 personas (DI LISCIA, 2011).

A pesar de las insistencias del colectivo médico no se aprobaron diversos proyectos para la obligatoriedad de la vacunación presentados desde 1871 hasta 1886 en la Provincia de Buenos Aires, luego en la Capital Federal y Territorios Nacionales (Ley 4.202, sancionada en 1903 y reglamentada en 1904). Esas discrepancias se deben al lobby ejercido por los médicos en determinadas jurisdicciones y a su incidencia política en los órganos legislativos, más que a razones técnicas concretas ya que se conocían con anterioridad las prácticas de antivariolización con vacunas animales.

La necesidad de legislar la obligatoriedad de la vacunación surgió paralelamente a la detección del aumento de víctimas mortales. Pero no fue una medida aceptada de manera fácil: la resistencia se observa tanto en la población como en las dificultades para distribuirla. La oposición puede sistematizarse en dos grandes grupos: por un lado, en los sectores populares, partícipes de una cosmovisión fatalista y también temerosos de aceptar un remedio que a la vez, producía la enfermedad (si bien atenuada); y por otro lado, en los profesionales y funcionarios, renuentes a poner en funcionamiento una medida reputada poco eficaz, engorrosa y costosa. Debemos aclarar que en este momento la discusión no sale de los límites de la Provincia de Buenos Aires; si bien era lógico plantear más allá de la provincia medidas semejantes, la imposibilidad política de hacerlo impidió generar un proyecto de alcance nacional.

La negativa de la población a aceptar libremente la medida iba unida a la dificultad de aislar a los afectados y prevenir el contagio, papel en el cual estaban directamente imbricadas las creencias y costumbres de los sectores populares y de la Iglesia. El relato del médico Lucio Meléndez sobre la primera epidemia de consideración, sucedida en 1871, expresaba éstas y otras dificultades, poniendo como principales causantes no sólo a la fatalidad sino a la ignorancia y la desidia. La "mortífera enfermedad" se dispersó desde los pueblos del Norte de la campaña bonaerense (San Pedro, Junín, Baradero, Zárate), por la costa del Río Paraná, hasta la provincia de Santa Fé y llegó al puerto de Rosario. El médico, indignado, 
resaltaba en exaltadas páginas a sus colegas que jamás había encontrado mayor resistencia en las personas adultas y en los padres de los niños para prestarse a recibir los beneficios de este verdadero e incontrovertible descubrimiento de Jenner. Unos aducían como causa, para prestarse a esta pequeña operación, la duda que si la viruela que se les trataba de inocular sería de buena calidad, otros la inutilidad del profiláctico, pues que si estaba previsto por Dios que sus hijos debían ser atacados por el flagelo y morir quizás por sus consecuencias, todo sería inútil. ¡Triste desengaño para el comisionado que en nombre de la ciencia y de la experiencia de tantos siglos recibía un no, fundado en un raciocinio tan ilógico, como basado en ideas de tanto salvagismo [sic] e ignorancia! (en DI LISCIA, 2011).

A esta situación se le agregaba la imposibilidad de aislar a los enfermos y muertos. El virus se dispersaba a partir del hacinamiento de las viviendas, en los lazaretos y hospitales, como luego confirmaría José Penna en la ciudad de Buenos Aires, y también en ocasión de ceremonias religiosas. La obligatoriedad terminaría, según la visión de los expertos, con la oposición soterrada y abierta a recibir el virus atenuado. Esta élite médica medía al resto de la sociedad bajo el parámetro de la ignorancia y/o la superstición; luchar contra una y otra era imposible sin el apoyo de las autoridades estatales o del sistema educativo; el primero no necesariamente de acuerdo con esta regulación y el segundo inexistente.

El primer proyecto para declarar la obligatoriedad de la vacunación surgió luego de la epidemia de fiebre amarilla de 1871 y fue presentado a la Legislatura por el Consejo de Higiene pública un año después pero no logró la aprobación. Esto demuestra la tibia influencia del principal órgano sanitario, situación que intentó modificar la Asociación Médica Bonaerense, corporación de facultativos formada recientemente en el escenario porteño (en DI LISCIA, 2011). En 1878, el médico vacunador Justo Meza presentó un proyecto a la Asociación, refrendado por Lucio Meléndez, Emilio Coni y Juan Díaz, donde expresaba que la vacunación debía ser obligatoria en todo el territorio provincial y realizarse entre los primeros seis meses y el año de vida; se establecía la revacunación a empleados y funcionarios públicos, se proponía a las municipalidades y médicos de campaña como organismos de control y se vinculaba la medida sanitaria con la alfabetización, ya que no podría admitirse a ningún alumno en las escuelas sin acreditación de estar vacunado. Se fijaban asimismo multas para quien infringiera este código. La presentación fue sin embargo rechazada por otros asociados, a pesar de que se publicaba acompañada del relato escalofriante de Meléndez sobre la epidemia de 1871. La argumentación general fue que la Asociación no tenía personería para dirigirse a las Cámaras, pero también en el proyecto se aducían razones administrativas sobre la forma de distribuir la vacuna, retrucando los argumentos anteriores sobre la resistencia. El médico Justiniano Ledesma señalaba así: "no creo que haya en nuestras poblaciones una resistencia obstinada a la vacunación, lo que solamente se observa es olvido e indolencia”, además, dejaba entrever los riesgos que la población observaba en la vacuna en tiempos de epidemia (LEDESMA, 1878, p. 404). 
Para Ledesma, el problema era el control efectivo del sistema público sobre los vacunados ya que si bien la obligación se iniciaba en el primer año de vida, recién a los siete años podría saberse si se había cumplido o no, es decir, cuando se ingresara al primer grado escolar. En ese ínterin, las epidemias podían atacar a la población y mucho más, a la infantil. A tales cuestiones, Meléndez había respondido expresando que los curas no administrasen el bautismo a quienes no estuviesen vacunados para lograr la protección frente a la enfermedad a recién nacidos o nińos pequeños, pero Ledesma se preguntaba cómo instrumentar una política de regulación sin una estructura y sin controladores (LEDESMA, 1878).

Frente a la inminencia del contagio, y en momentos críticos, se forzaba efectivamente a la población a vacunarse. Pero para ello se requería evidentemente de un "poder de policía" que los médicos porteńos estaban lejos de contar. Ponían como ejemplo otras áreas del país, como la provincia de San Luis donde el facultativo Benjamín Dupont había ingresado en casas muy humildes para vacunar. En Buenos Aires, los estudios estadísticos de Emilio Coni establecían que tres cuartas partes de los niños nacidos no se vacunaban y José Penna señalaba similares cuestiones. El suministro del "virus vaccínico" constituía un problema anexo, ya fuera en relación a su calidad es decir, sin contaminación de otras patologías como la sífilis o la tuberculosis, como a su cantidad, ya que era necesario generar las placas para llegar a todos los médicos en los distintos distritos de la campaña o en los barrios de la capital porteńa. El conservatorio de vacuna del Instituto Veterinario Santa Catalina en Monte Grande proveía del virus sobre todo al personal encargado de la vacunación en la ciudad de Buenos Aires, que eran un médico y entre cinco o seis practicantes de medicina, es decir, estudiantes avanzados y a los 80 partidos bonaerenses. Según Justo Meza, la cantidad de vacunas era suficiente para abastecer a todos los que la requiriesen, incluso a los facultativos que difundían la medida entre su clientela. Esta cuestión es interesante puesto que plantea que la vacunación era también un asunto privado y no únicamente público y por lo tanto, era preciso examinar su eficacia y vencer sucesivas resistencias que provenían de ámbitos y sujetos muy diversos. Había personas que, por haber sufrido la viruela y sobrevivido, consideraban que no era necesario vacunarse. Los médicos debían informar las dosis y repeticiones pero rara vez lo hacían; disponían del virus gratuitamente y cobraban por su colocación. Además, "curanderos y medicastros", parteras y flebótomos, colocaban la vacuna ante la ausencia de médicos y practicantes, y en esos casos lo hacían siempre en forma ineficiente (CONI, 1879).

En 1878 el proyecto de vacunación obligatoria no fue aprobado; en 1879 lo volvió a presentar uno de los legisladores, Bermejo, pero la confusa situación política nacional de 1880 hizo imposible un avance en este sentido. Luego de un prolongado conflicto, se resuelve la subordinación de la provincia de Buenos Aires al poder federal, y Buenos Aires se transforma en Capital Federal. En ese momento, llega a la presidencia de la Nación Julio Argentino Roca e inicia un gobierno conservador que estructuró el Estado nacional durante una etapa de gran expansión económica. 
En 1882, la Asociación logró el acuerdo de la corporación médica y presentó otro proyecto para impulsar la vacunación obligatoria en la municipalidad porteña (firmado por José María Ramos Mejía, Emilio Coni, Parodi, Salvarezza y Pirovano) pero no se obtuvo la aprobación; tampoco para el Proyecto presentado en 1881 por el entonces intendente porteńo Torcuato de Alvear al Congreso Nacional, ni para el de 1883, elevado por Mariano Demaría, director del Instituto Veterinario citado anteriormente. Alvear expresaba la necesidad de intervenir en conventillos y vacunar masivamente, con o sin el acuerdo de sus habitantes, culpabilizando a estos sectores de distribuir la enfermedad.

En ese momento, los higienistas se lamentaban de que los médicos del Congreso Nacional y de la Legislatura provincial porteña no prestasen atención a una cuestión de tanto interés para la salud humana y sin embargo, en aras de la expansión agrícola-ganadera, se ocupasen de la sarna de las ovejas o de problemas veterinarios similares, como indicaban irónicamente Coni y Penna (en DI LISCIA, 2011). Había ya profesionales que formaban parte del gobierno nacional y provincial, pero a este sector de médicos, deseosos de implementar las reformas, no era fácil presionarlos. Entre 1870-1890, los casos más notables fueron el de Manuel Montes de Oca, quien participó en la legislatura porteña, fue diputado nacional y ministro de relaciones exteriores durante el gobierno de Avellaneda; Mauricio González Catán, legislador provincial en 1870 y nacional en 1880, partidario de Roca; Guillermo Rawson, diputado, senador y ministro del interior durante la presidencia de Mitre y Eduardo Wilde, partidario de Roca primero y después de Juárez Celman, de quien fue ministro de instrucción pública en 1882 y ministro del interior en 1886. Estos cuatro médicos también tuvieron una actuación destacada en la Academia y Facultad de Medicina y en el Consejo y Departamento de Higiene (GONZÁLEZ LEANDRI, 1999).

Tal situación, sin embargo, comenzaría a cambiar en los ańos siguientes, cuando los médicos pudieron imponer de forma más eficaz sus intenciones higiénicas a un espectro social mayor. Incidió en la aprobación una preocupación social general en el colectivo médico por las enfermedades contagiosas (ARMUS, 2011) y de manera específica, apuntalaron la medida las epidemias entre los indígenas, llevados a Buenos Aires luego de las campañas de exterminio (DI LISCIA, 2011).

En 1881, Louis Pasteur bautizó como "vacuna" a un producto artificial para inmunizar contra la rabia, en homenaje a Jenner. Esos estudios rápidamente se conocieron en el ámbito local, otorgándole a la vacunación una sanción científica mayor. Casi al mismo tiempo surgió en Francia la Liga Internacional Antivacunas que realizó congresos en distintas ciudades europeas (AMORETTI, 1886). En Gran Bretaña apareció también una organización similar que desde 1853 luchó por limitarla en pos de la defensa de valores liberales, y como intervención autoritaria sobre los sectores populares, que obtuvo en 1907 un triunfo con la “objeción de conciencia” (DURBACH, 2005).

Hacia finales del siglo XIX se dispone en Argentina de testimonios de descontentos y renuencias individuales o familiares pero no una forma de resistencia organizada en contra de la vacunación debido a la aceptación de un amplio arco ideológico de intelectuales y otros 
profesionales que acompañaron a los médicos en la organización estatal laica. Sin embargo, la vacunación no era un hecho que se producía de una vez y para siempre; requería varios intentos y en ese ínterin las personas vacunadas inicialmente no retornaban para que los facultativos revisaran si se había formado la pústula que indicaba la reacción inmunológica positiva. Por ello en las estadísticas parciales sobre vacunados en la ciudad de Buenos Aires, entre 1878-1886, los positivos fluctuaron entre un 37 a un $59 \%$, los negativos fueron del 17,4 a un $8,1 \%$. Los ignorados iban del 45 al 33,4 \%. Las primeras medidas, una vez otorgada la obligatoriedad, implicaron el recorrido de los barrios porteños con la vacunación a domicilio. De acuerdo con el discurso médico, criollos e inmigrantes recién llegados a los pobrísimos conventillos se negaban a este beneficio por su ignorancia y no acataban tampoco la revacunación (AMORETTI, 1886).

Se trató de una instancia impuesta como modelo científico para luchar contra la viruela y como ejemplo para extender los preceptos higiénicos en general. Esta medida se constituyó en bandera y en uno de los principales recursos de un Estado supuestamente moderno, con su aparición en lugares ignotos de la geografía nacional, y en los territorios arrebatados a las poblaciones originarias, donde se dibujaba un nuevo mapa con población europea, como veremos en el apartado siguiente.

\section{Una comunidad nacional inmunizada}

En 1880, se organizó el Departamento Nacional de Higiene (DNH) con potestad en la Capital Federal y los Territorios Nacionales entre cuyas funciones estaba la lucha antiepidémica. En las provincias históricas existían Consejos de Higiene y en la Capital (Buenos Aires) se creó la Asistencia Pública, que incluía la tarea de vacunación antivariólica. Al frente del DHN estuvieron reconocidos facultativos, tanto de perfil político como técnico: José María Ramos Mejía, Eduardo Wilde, Carlos Malbrán, José Penna, Gregorio Araoz Alfaro y Miguel Sussini ${ }^{6}$. En 1913, se crearon Asistencias Públicas en los Territorios Nacionales con similares propósitos higiénicos.

Las posibilidades de la vacunación abrieron nuevos horizontes. Las técnicas para obtenerla de animales con virus similares eran conocidas antes de su aplicación. Se requerían vacunos para escarificar, métodos para conservar la pulpa de la linfa y un sistema de atenuación de los virus para limitar su peligrosidad. Las escenas de vacunación antes del Conservatorio oficial deberían ser curiosas, con los animales que acompañaban al vacunador en su tarea por los distintos domicilios. En los manuales y tesis se indicaban escrupulosamente las posturas del médico y de los pacientes y cómo tomar de las pústulas la linfa del vacuno con el virus e

\footnotetext{
${ }^{6}$ El listado completo de autoridades y sus principales esfuerzos en Biernat (2015). Una síntesis de las políticas sanitarias en Veronelli y Veronelli Correch (2004) y Di Liscia (2017).
} 
introducirlo en el organismo humano (DIAZ, 1876; AMORETTI, 1886). Las indicaciones nos permiten observar una práctica artesanal, muy similar a la inoculación.

Al generalizar la vacunación y ampliar la medida con la obligatoriedad, también cambió la escala de elaboración y se montaron instituciones ad hoc. En el caso argentino, prácticamente toda la producción se concentró desde 1890 en el Conservatorio Nacional de Vacuna y en el Instituto Veterinario de Santa Catalina en la Provincia de Buenos Aires. Hacia 1901, se obtenía en el Instituto de Bacteriología en la Capital Federal, denominado en 1916 Instituto de Bacteriología, Química y Conservatorio de Vacuna Antivariólica ${ }^{7}$. Otro Instituto de similar denominación dependía del Ministerio de Agricultura con relación a las enfermedades del ganado y otras cuestiones veterinarias y desapareció en 1916.

El procedimiento se exponía minuciosamente con el método de Cow Pox, desde la elección del "vaccinógeno" (terneras de raza Hereford o Durband), la manera de lavar e inocular en la región abdominal con linfa el virus hasta la recolección de la pulpa para asegurar una preparación en condición antiséptica, dado que la vacunación podía producir nuevas patologías (LARGUÍA, 1902). Una de las principales renuencias populares provenía del conocimiento de la transmisión de enfermedades graves como la sífilis y la tuberculosis o infecciones gangrenosas a través de vacunas contaminadas.

La conservación del producto ya estaba resuelta al menos técnicamente y ese procedimiento se conocía desde 1850: una mixtura de linfa vacunal con glicerina permitía evitar la descomposición y prolongar su acción ${ }^{8}$. Por lo tanto, luego de la extracción del material, se procedía a realizar una pulpa con ese producto y glicerina, extrayendo restos de piel y sangre, y a colocarla en 10 placas; el animal se destinaba a necropsia para certificar su salud y la existencia del Cow Pox. Dos de las placas obtenidas en esa serie se destinaban al Laboratorio Bacteriológico para certificar ausencia de otros microorganismos; con otras dos se vacunaba a varias personas en el Instituto. Las vacunas estaban "puras" (sin bacterias) pero podían ser inertes y en consecuencia, la cepa de esa serie se descartaba al no tener efecto inmunizador. Si daban resultado positivo, se preparaban las placas para distribuir en toda la nación. Seguidamente, se procedía a la conservación, instancia delicada y que requería otros cuidados, ya que la linfa glicerinada y seca se disponía en placas a $120^{\circ}$ durante media hora y luego se recubrían de parafina para asegurar una duración de 3 a 4 meses en lugar fresco. Cada placa llevaba el nombre del "vaccinógeno" y la fecha (LARGUÍA, 1902).

En esta experiencia veterinaria y práctica de laboratorio primaba la importancia de la prueba en seres humanos para la decisión final. Los médicos y otros técnicos de laboratorio

\footnotetext{
${ }^{7}$ La institución cambió de denominaciones y amplió sus funciones; fue sucesivamente Instituto Nacional Carlos Malbrán en 1941, Instituto Nacional de Microbiología en 1957 e Instituto Nacional de Microbiología Dr. Carlos Malbrán en 1967.

${ }^{8}$ L'ERADICATION Mondiale de la Variole. Rapport final de la Comission Mondiale pour la Certification de la Eradication de la Variole. Genève: OMS, 1980.
} 
se hicieron con las decisiones, aupados por el $\mathrm{DNH}$ y desplazaron a los veterinarios quienes promovieron quejas e incluso un proyecto de Ley, aunque sin éxito?.

Luego de la producción se iniciaba la distribución, y para lamento de los encargados, había un notable desperdicio. Las placas llegaban por correo en paquetes de hasta 50 a los Consejos de Higiene de las provincias. Entre 1875-1901 se habían distribuido 2.106.070 placas con las cuales vacunar a más de 4,5 millones de personas, cerca del total de habitantes del país. Pero sólo se registraban 323.000 personas vacunadas y de ellas, sólo estaban inmunizadas fehacientemente 231.947; 12.615 habían dado resultados negativos y de 24.758 se ignoraba el resultado. La Asistencia Pública de Buenos Aires podría haber vacunado el doble, al igual que las provincias de Santa Fe, Córdoba, Tucumán y Mendoza. Las placas producidas con tanto cuidado se desaprovechaban; incluso había particulares que seguían vacunando con lo que "el Estado suministra gratuita y liberalmente" (LARGUÍA, 1902, p. 52). El problema fundamental parecía ser la distribución dado que se utilizaba menos del $10 \%$ del envío y de manera irracional porque su totalidad hubiese permitido alcanzar la inmunización universal de manera temprana.

Las epidemias no cejaron, en un Estado que no podía ejercer la potestad, por ejemplo, de impedir a los inmigrantes ingresar al país si no estaban vacunados o ingresar en las viviendas y vacunar a los niños sin acuerdo de los progenitores. Dependía entonces de un acuerdo general de la población en aceptar la vacunación y acudir a los centros oficiales. Tales dificultades se debían al escaso compromiso de las autoridades provinciales y aún de la Ciudad de Buenos Aires, cuya Asistencia se suponía modélica en la atención médica de entonces. Esas cuestiones llegaron seguramente a los oídos oficiales, dado que las Tesis médicas tenían "padrinos" y el de Larguía era José Penna, quien también se había ocupado de la viruela (PENNA, 1885). Su carrera fulgurante incluye la dirección de la Asistencia Pública en 1906 y la de Diputado Nacional entre 1910-1914, además de presidente del DNH hasta 1916.

La insistencia tanto de Carlos Malbrán ${ }^{10}$ como de Penna como autoridades al frente de esas instituciones de primera línea impregnó de una dinámica diferente al sistema sanitario en su conjunto. Se obtuvieron recursos otorgados por el Congreso de manera extraordinaria

\footnotetext{
${ }_{9}^{9}$ Agradezco a Juan Pablo Zabala la mención de esta polémica y del proyecto de Ley enviado en 1915 por la Sociedad de Medicina Veterinaria al Congreso de la Nación para impedir el traspaso a la órbita del DNH.

${ }^{10}$ Carlos Malbrán (1862-1940), catamarqueño de origen, se graduó en Buenos Aires con una tesis sobre el cólera. Su formación incluyó visitas a otros centros y contactos con investigadores destacados; así, en enero de 1888 fue encargado por el Gobierno Nacional para efectuar estudios de higiene y bacteriología en Munich y en Berlín. Se especializó en bacteriología y seroterapia y en 1893, estuvo a cargo de la Sección Bacteriología del DNH. Su carrera académica incluye el acceso como profesor y vicedecano en la Facultad de Ciencias Médicas de la Universidad de Buenos Aires y la elección en la Academia Nacional de Medicina. Fue además Senador Nacional por la Provincia de Catamarca. Malbrán llegó al máximo organismo sanitario argentino por la renuncia de Eduardo Wilde, quien había sido incapaz de controlar la epidemia de peste, y entre sus mayores logros se cuenta la organización del Instituto de Bactereología, vinculado con la generación de sueros y vacunas (DI LISCIA, 2017).
} 
y con gran liberalidad, como indicaron sus predecesores. Con esos emonumentos se organizaron campańas sistemáticas de vacunación, primero en los barrios porteńos y luego en los Territorios Nacionales desde los inicios del Siglo XX. El escenario inicial se amplió más allá de los habitantes de Buenos Aires para incluir a los de los Territorios Nacionales ${ }^{11}$. Se amplió la vacunación a los inmigrantes extranjeros y y a sus familias, sobre todo en las escuelas ya que la práctica era obligatoria en las instituciones educativas. Se indicaba que:

La vacunación es indiscutiblemente la forma profiláctica más exacta, más perfecta y más segura y al mismo tiempo la más fácil de poner en práctica con el fin de proporcionar esa resistencia orgánica artificial. [...] La inmunización artificial por la vacunación, juzgada por los resultados obtenidos en la viruela es superior, considerados todos los otros medios preventivos usuales, por su acción es tan cierta y positiva que sola basta para extinguir las epidemias. El aislamiento, el saneamiento del foco, la desinfección misma le son muy inferiores (PENNA; MADERO, 1910, p. 96).

En 1912, Penna envió un Proyecto de Ley para implantar la obligatoriedad a todo el territorio nacional, pero el Poder ejecutivo debía acordar con los gobiernos de las provincias su aplicación (VERONELLI; VERONELLI CORRECH, 2004). Esa legislación no se aprobó dado que implicaba una injerencia, quizás intolerable, en los gobiernos provinciales sobre sus propias capacidades de control de la viruela. Sin embargo, la Ley 4.202 sancionada en 1903 se mantuvo y fungió para todo el territorio nacional hasta su derogación.

Pero otras regulaciones paralelas se instituyeron para fortalecer las decisiones sanitarias, como la obligatoriedad de la vacunación en los escolares, establecida con la Ley 1.420. Ese punto fue esencial para lograr no sólo la extensión de la inmunización sino la ampliación de medidas científicas en el imaginario popular. Para ello, colaboró la expansión paralela de la educación pública, de manera tal que ambos procesos, el pedagógico y el médico, se retroalimentaron en la noción formativa de una nación moderna y colaboraron, sin excluir a otras razones de orden familiar o médico, en la aceptación de la medida. El Cuerpo Médico Escolar, dependiente del Consejo Nacional de Educación, organizado en 1884 por la élite médica, era el encargado de certificar la vacunación y en ocasiones, organizaba también su aplicación. La intersección entre ambos organismos se verifica en las publicaciones, donde se difundieron profusamente no sólo las ventajas de la inmunización universal sino también las campañas y las formas de producción de la vacuna (ALVAREZ, 1917). Si bien, como hemos analizado, la instrucción primaria no alcanzaba a la totalidad de la población, la

\footnotetext{
${ }^{11}$ Sobre las epidemias de viruela en el período se informó a través de la Sección de Profilaxis del DNH de las sucedidas, por ejemplo, en la Provincia de San Luis en 1907 (LOZANO, 1908). Este organismo nacional tenía problemas para obtener información fehaciente de los gobiernos provinciales, reacios a enviarla (CIRCULAR del Ministerio del Interior solicitando de los gobiernos provinciales el envío de datos estadísticos. Anales del Departamento Nacional de Higiene, año XV, n. 6, p. 318-319, 1908).
} 
escolarización fungió como un poderoso instrumento para auspiciar la vacunación (DI LISCIA, 2004).

La preparación de las campañas, con su organización de itinerarios, agentes vacunadores y coordinación con ferrocarriles y espacios para vacunar seguramente insumía gran parte de las tareas de la Sección de Profilaxis del DNH, a cargo de otro prominente higienista, Nicolás Lozano ${ }^{12}$. Las políticas sanitarias se transformaron en instituciones portátiles, con la promesa de llegar a todos los rincones de la República. Los agentes sanitarios, generalmente practicantes o auxiliares, viajaban por desiertos y cruzaban montañas y ríos para llegar a ignotos pueblos, donde auxiliados por autoridades locales - policías y maestras -, desplegaban sus lancetas y placas y allí vacunaban a familias enteras ${ }^{13}$.

La mortalidad por viruela disminuyó notablemente; en las escasas obras que disponemos respecto a estos aspectos discriminados para todo el país, se daba cuenta prácticamente de la desaparición en poco tiempo: Entre 1911-1914, hubo 4.420 decesos por esta causa, (1911: 4.024; 1914: 17 casos) por lo que la mortalidad por viruela es insignificante, con tendencia decreciente. En ese momento, la mortalidad por otras enfermedades (como la bronconeumonía) era de 24.725 personas (PENNA; RESTAGNIO, 1916), Pero es importante destacar que para esta última no había paliativos, como los sería posteriormente la terapia antibiótica, mientras que para la viruela la aplicación de la vacuna se planteaba como una única y posible solución.

En 1921, se fabricaron 1.967.770 dosis, cuando el país tenía más de 8 millones de habitantes. Casi un centenar de personas trabajaban sólo en el proceso su confección en el Instituto citado, centralizando su accionar para todo el país. Se utilizaron ese año 627 terneros y se obtuvo $25.361 \mathrm{~g}$. de linfa para los casi dos millones de placas ${ }^{14}$. Esta fue una de las escasas políticas nacionales exitosas de las que el país podía enorgullecerse puesto que coordinaba desde la producción de vacunas hasta su distribución.

Como otros países, Argentina participó de los organismos internacionales en relación con el control epidémico. La viruela era una de las enfermedades registradas por los afanes de la entonces Oficina Panamericana (luego Organización Panamericana de la Salud). En los

\footnotetext{
${ }^{12}$ Nicolás Lozano (1864-1938) se doctoró en 1890; en su tesis incluía aspectos a las cuarentenas y proceder a la desinfección de los navíos. En 1904 era médico en el sistema de inspección de navíos y luego, ingresó en el DNH como Jefe de la Sección a cargo de la vacunación. Fue co-autor con Penna de un Proyecto, aprobado como Ley de Defensa Sanitaria en 1912, que buscaba integrar todos los servicios sanitarios y extender el control del DNH a todo el territorio nacional. En 1917 todavía pertenecía al staff del DNH y en esas condiciones participó con un trabajo sobre la etiología y profilaxis de la tuberculosis en un congreso internacional en Estados Unidos (en DI LISCIA, 2018). Hacia 1930, tenía destacada participación sobre asuntos de interés sanitario a nivel nacional y fue también presidente de la filial local de la Cruz Roja, agencia humanitaria internacional (LOZANO, 1932).

${ }^{13}$ En trabajos anteriores hemos dado cuenta, de manera pormenorizada, de estas campańas de vacunación sobre todo en los Territorios Nacionales, llevadas adelante desde la Sección de Profilaxis del DNH (DI LISCIA, 2010).

${ }^{14}$ VIRUELA. Boletin de la Oficina Sanitaria Panamericana, v. 16, n. 8, p. 760-771, 1937.
} 
años Veinte, en esta agencia se publicaron mes a mes las estadísticas de los casos de viruela y en esos listados se denota el avance triunfante sobre la viruela ${ }^{15}$. En determinadas provincias argentinas, como se observa en Santa Fe, la prensa hizo un seguimiento detenido de estos brotes, indicando la necesidad de la vacunación ${ }^{16}$. A manera de ejemplo se informaron un caso en Argentina y 223 en Brasil, en este último con 131 muertos $^{17}$. En 1928, una síntesis exhaustiva de los delegados Laurentino Olascoaga, Nicolás Lozano y Alfredo Sordelli ante la $8^{\circ}$ Conferencia Panamericana especificaba que la enfermedad estaba totalmente desaparecida en el país. Otros índices halagüeños, como el descenso de la mortalidad general e infantil (16/1000 y 116/1000 respectivamente), hacían de Argentina el país con mejores perspectivas demográficas dentro del conjunto latinoamericano ${ }^{18}$.

En los años Treinta, se citan campañas en el verano en los territorios del Sur para recorrer caminos de imposible tránsito en invierno. El Jefe de la Sección de Vacuna indicaba la distribución de 670.245 placas, con las cuales se vacunó a 127.790 y revacunó a 319.072 en todo el país. El accionar inmunizador no estaba completo ya que se debía periódicamente volver a vacunar a la población, y por ello, se detallaban como antaño las formas de obtención de placas a través de las terneras y la escarificación ${ }^{19}$. Además de la vacuna, se imponían restricciones a la circulación y el aislamiento de los contagiados, que no era posible mantener por un largo período. En relación a una epidemia de viruela declarada en Entre Ríos, al temer que pasase a Santa Fé, las autoridades recorrieron la costa vacunando y re-vacunando e impidieron el ingreso de provincias vecinas ${ }^{20}$.

La vacunación se transformó en una rutina y luego se relegó frente otras urgencias, como las campañas y proyectos en pos del control de la malaria y el paludismo, la peste, el tifus y la uncinariosis $^{21}$. Por entonces ascienden al escenario público numerosos reclamos y demandas frente a problemáticas socio-sanitarias no atendidas, en pos de una agenda materno-infantil y de la percepción en general de una crisis sanitaria (BELMARTINO, 2005). La viruela pasó a ser una enfermedad controlada pero no eliminada totalmente y ese ascenso de casos se verificó a mediados de los años Treinta. En 1936, 18 contagios de trabajadores de yerbatales en la Provincia de Misiones, lindante con Brasil, forzó a aislar el foco y vacunar o revacunar a 250.000 personas $^{22}$. Y un año después hubo contagios en Corrientes, Misiones y Entre Rios además de 349 casos en Jujuy, con una frontera cercana a Bolivia, debido a la zafra ${ }^{23}$. En el

\footnotetext{
15 Sobre la OPS-PAHO, ver Cueto y Palmer (2015).

${ }^{16}$ EPIDEMIA de viruela. Santa Fé, Diario, 10 feb. 1923.

${ }^{17}$ LA VIRUELA en las Américas. Oficina Sanitaria Panamericana, año 2, n. 304, 1924.

${ }^{18}$ PROGRESOS realizados en higiene e informes sanitarios. Boletín de la Organización Panamericana de la Salud, v. 7, n. 1, p. 273-280, 1928.

${ }^{19}$ VIRUELA. Boletín de la Oficina Sanitaria Panamericana, v. 10, n. 10, p. 1.328-1.331, 1931.

${ }^{20}$ EPIDEMIA de viruela. El Orden, Diario, 27 oct. 1935.

${ }^{21}$ VIRUELA. Boletín de la Oficina Sanitaria Panamericana, v. 15, n. 7, p. 679-685, 1936.

${ }^{22}$ Idem.

${ }^{23}$ LA SANIDAD en Argentina. Boletin de la Oficina Sanitaria Panamericana, v. 16, n. 6, p. 509-522, 1937.
} 
caso de las provincias norteñas, la migración de mano de obra era un punto importante a considerar, pero también se mencionaron "supuestos fracasos" en la vacunación dado que las placas no habían podido conservarse en condiciones óptimas ${ }^{24}$.

Otro brote, esta vez en Punta Alta (ciudad de la Provincia de Buenos Aires), dio lugar a una medida contundente ya que un Decreto del entonces Presidente de facto obligó a los empleados públicos nacionales y municipales a vacunarse en todo el país. Además, todo el que iniciaba un trámite debía demostrar que lo estaba a través de un Certificado ${ }^{25}$. Esta constancia sólo se solicitaba antes a inmigrantes y a escolares, por lo que de esta manera se amplió a un conjunto mayor de adultos supuestamente ya inmunizados.

El Instituto de Bacteriología antes citado producía nuevas vacunas como la antirrábica; sueros, como el antitetánico y antiofídico y otros productos biológicos como la insulina. Pero ninguno tenía la circulación y masividad de la vacuna antivariólica, de la que se fabricaban cientos de miles de dosis ${ }^{26}$. El eje de las políticas de vacunación era claramente estatal, desde una institución pública, con vacunas producidas en serie y prácticas que continuaron con pocos cambios hasta los años Setenta del Siglo XX.

Desde 1919, debido a las restricciones a las importaciones y de una política de expansión local, la producción local de medicamentos cubría el 99,25 \% del mercado total. En este mercado participaban empresas argentinas y extranjeras que debían importar drogas y principios activos (ROMÁN, 2020; CAMPINS; PFEIFFER, 2017)27. Este dinámico sector industrial, sin embargo, no tenía entre sus objetivos la producción de la vacuna antivariólica dado que estaba totalmente abastecido por el sector público, establecido con anterioridad.

Ahora bien, en cincuenta ańos, las técnicas para vacunar se habían transformado muy poco en Argentina y tampoco la producción del material había sufrido cambios destacados. Desde 1885 la primera generación de científicos herederos de la Revolución Pasteuriana había explorado diferentes caminos en relación con la atenuación de virus por alta temperatura, agentes químicos, uso de determinadas cepas o el cultivo celular, que a partir de 1949 permitió la fabricación de vacunas virales abriendo un nuevo capítulo tanto técnico como científico (MOULIN, 2010). La producción de vacunas era a mediados de los años treinta, de acuerdo a la agencia a cargo, más eficaz dado que menos personas producían más dosis. Alvarado, reconocido sanitarista a cargo de esa sección, indicaba que en 1936, 30 empleados del Instituto con 222 terneros habían logrado aumentar a $55.319 \mathrm{~g}$ de linfa y así producir 2.528.530 dosis ${ }^{28}$. Se mezclaba el Cow Pox con glicerina como en otro

\footnotetext{
${ }^{24}$ ARGENTINA. Boletín de la Oficina Sanitaria Panamericana, v. 18, n. 8, p. 875-879, 1939.

${ }^{25}$ VIRUELA. Boletín de la Oficina Sanitaria Panamericana, v. 16, n. 8, p. 760-771, 1937.

${ }^{26}$ LA SANIDAD en Argentina. Boletín de la Oficina Sanitaria Panamericana, v. 16, n. 6, p. 509-522, 1937. Eso fue posible porque desde 1914 se proveía gratuitamente de los mataderos municipales de glándulas y otros productos ortoterápicos para realizar estos medicamentos (ROMÁN, 2020).

${ }^{27}$ Ver asimismo Bramuglia, Abrutzky y Godio (2012).

${ }^{28}$ VIRUELA. Boletín de la Oficina Sanitaria Panamericana, v. 16, n. 8, p. 760-771, 1937. Carlos Alberto Alvarado (1904-1986) fue un médico especialista en sanidad sobre todo rural, funcionario encargado de cam-
} 
tiempo, aunque por entonces ya existían otras posibilidades que iban más allá de la cantidad e incluían la conservación y el tiempo de duración de la inmunidad. Ambas cuestiones son muy importantes, ya que determinan además la estrategia de la cantidad, en virtud de necesidades anuales de menores volúmenes pero a la vez un suministro permanente con diferente sistema de transporte. Por ejemplo, la "vacuna seca" experimentada en el Institut Pasteur de Paris y Saigón obtenía mejores resultados que las húmedas porque era más fácil de distribuir ${ }^{29}$ y estudios realizados en Alemania y Estados Unidos sobre la inmunidad obtenida a partir de la linfa vacuna, que era la utilizada en Argentina, desestimaban que fuera útil más allá de dos años, obligando a la permanente revacunación ${ }^{30}$.

La apuesta nacional había sido formalizar políticas públicas centralizadas y controlar la producción, conservación y distribución oficial con cobertura universal, a costa de gestar y mantener el sistema con bajo nivel de innovación. Unos de los pocos cambios fueron el reemplazo de placas de vacunas por tubos capilares para conservación de la linfa y pomos de 25 a 50 dosis, cuando la Sección de Vacuna pasó a formar parte directa del Instituto de Bacteriología (SUSSINI, 1939). Este organismo había sido punta de lanza en investigaciones biológicas y fisiológicas, de la mano de Rufolf Krauss primero y luego de Alfredo Sordelli, que luego quedaron adormecidas por la producción rutinaria de sueros y vacunas (KREIMER; FERPOZZI, 2016).

Entre 1945-1955, se suceden toda una serie de modificaciones importantes en el escenario sanitario nacional, cuyos antecedentes es preciso buscar en políticas estatales de intervención y gestión pública desde los años Veinte, pero que introducen nociones como el "derecho a la salud"31. Entre las campañas realizadas, la viruela no tenía la centralidad de otras épocas, razón por la cual reaparecieron brotes hacia 1949 (RAMACCIOTTI, 2015). Se debatió si se trataba del virus de la Viruela Mayor o del Alastrín, con efectos menos graves en el organismo humano. Los 365 casos impactaron sobre el sistema de vacunación ya que se denunció que la inmunización era insegura por utilizar material refrigerado por más de un día; tal cuestión entonces invalidaba el proceso en su conjunto y volvía a poner en pie el dilema de qué producto utilizar y cómo conservarlo de manera adecuada para su distribución.

pañas contra la malaria y el paludismo en Argentina durante la etapa peronista (1945-1955); posteriormente estuvo a cargo de la Dirección de erradicación de la malaria en la OMS y fue ministro de salud en la Provincia de Jujuy entre 1955-1966, donde llevó adelante un programa de salud rural y de producción de vacunas. Ver su accionar en Alvarez (2004).

${ }^{29}$ VIRUELA. Boletín de la Oficina Sanitaria Panamericana, v. 10, n. 10, p. 1.328-1.331, 1931.

${ }^{30}$ VIRUELA. Boletin de la Oficina Sanitaria Panamericana, v. 15, n. 7, p. 679-685, 1936.

${ }^{31}$ Ramón Carrillo, emblemático sanitarista y primer ministro del área, consideraba que la viruela ya era una enfermedad "eliminada" por una lucha eficaz llevada a cabo con la vacunación de carácter obligatorio. Con metáforas bélicas, por otra parte muy comunes en el lenguaje médico de entonces, la viruela había sido una plaga ya vencida, gracias en parte a la obligatoriedad de la vacuna que consideraba esencial para valorar con un alto puntaje las políticas sanitarias de una nación. Así, en una contabilidad general de indicadores, los países con la antivariólica compulsiva debían calificarse con 100 puntos mientras que los que no tenían esa legislación con 0 puntos (CARRILLO, 1949). 
En 1950, se deslizó la denuncia de que el regreso de la enfermedad se debía a que la "vacuna de vitrina", es decir, la que se conservaba sin refrigeración, no preservaba del contagio. Además, habían declinado las campañas de vacunación ${ }^{32}$. El Consejo Nacional de Educación puso en marcha al sistema de sanidad escolar para difundir (otra vez!) las ventajas de la vacunación, y en el relato del encargado se describía paso por paso la fabricación de la vacuna, para dar tranquilidad a la población sobre las condiciones higiénicas y las medidas de conservación, enfatizando el uso de cámaras por tres meses entre $4^{\circ}$ y $8^{\circ} \mathrm{C}$ y sólo vacunas disecadas en condiciones especiales. En las técnicas para vacunar se volvía a insistir, un siglo después, en que "en el sexo femenino se prefiere la aplicación en el muslo, para evitar la exteriorización de feas cicatrices" (HANSEN, 1954, p. 10).

En 1957, se indicaba que sólo un 40 \% de la población estaba correctamente inmunizada, de acuerdo a las autoridades nacionales ${ }^{33}$. Por entonces, y haciéndose eco de tal preocupación, se reprogramaron campañas masivas y se utilizó en el Norte del país una nueva vacuna confeccionada entre el ahora denominado Instituto Nacional Carlos Malbrán y la OPS (RAMACCIOTTI, 2015). Estamos aquí ya frente a otro proceso, en el camino de la erradicación, que vamos a analizar en el próximo apartado.

\section{La extirpación total de una enfermedad}

Desde las declaratorias de 1948 de la OMS hasta la erradicación efectiva en 1980 median más de treinta años. Estados Unidos, a través de la OPS, generó programas específicos en América a partir de 1949, pero a mediados de los ańos Sesenta, se produjo un nuevo impulso al observar que poco se había avanzado en el proceso planteado por sucesivas Asambleas y otras reuniones internacionales (RODRIGUES, 1975) ${ }^{34}$.

Es interesante la relación entre campañas de erradicación y Guerra Fría dado que la decisión se tomó en base al apoyo organizacional y técnico de ambas potencias, Estados Unidos y la URSS. Podemos especular en su papel para anudar lazos en el caso latinoamericano, ya que fue uno de los ejes en el Encuentro de Punta del Este, de 1961 y nos permitiría entonces otra mirada sobre actores y temáticas presentes en las relaciones interamericanas ${ }^{35}$.

\footnotetext{
${ }^{32}$ VIRUELA. El Litoral, Diario, 17 nov. 1950.

${ }^{33}$ PELIGRO de epidemia de viruela. El Litoral, Diario, 5 jul. 1957.

${ }^{34}$ La OMS fue establecida en 1948 y desde sus inicios, sucesivas Asambleas Mundiales instaron a los Estados miembros a tomar todas las medidas para controlar la viruela. En 1953, el primer Director General, el Dr. Brock Chisholm, hizo un intento infructuoso de persuadir a la Asamblea emprender una iniciativa mundial para un programa de erradicación. Cinco años después, el delegado soviético, Viktor Zhdanov, convenció a la Asamblea de aceptarlo, pero solo se proporcionaron fondos mínimos. Aunque 1967 la enfermedad fue eliminada de una treintena de países de Asia, África y Sur América, el núcleo duro del problema persistía, es decir, el subcontinente indio y la mayoría de los países en África subsahariana, donde no hubo mayores cambios hasta finales de los años setenta (FENNE; HENDERSON; ARITA; JEZEK; LADNYI, 1988, mi traducción).

${ }^{35}$ Como plantean Calandra e Franco (2012), dichas relaciones se tejen más allá de los actores tradicionales
} 
Dos años después de esta reunión cumbre, se reunieron los Ministros de salud de los países de la Cuenca del Plata, y con el apoyo del Banco Interamericano de Desarrollo, se formalizaron declaraciones sobre el control de enfermedades transmisibles. La viruela tenía un lugar especial en estas conversaciones de 1963 entre funcionarios de alto nivel de Argentina, Brasil, Paraguay y Uruguay para coordinar las campañas de sostén de manera articulada entre las fronteras. Entre las acciones concretas se bregaba en la promoción de servicios para diagnóstico, en las reuniones entre los jefes de las campańas y en el incremento de la producción de "vacuna liofilizada" de buena calidad para reemplazar la glicerinada ${ }^{36}$.

Veamos la situación desde Argentina, donde se había sancionado en 1960 la Ley no 15.465 de Salud Pública que obligaba a la declaración de enfermedades infecciosas; entre ellas, la viruela y el Alastrín (mencionado aquí como un virus diferente) dentro del "Grupo A”. Los profesionales de la salud - incluidos médicos, veterinarios, patólogos, obstetras, odontólogos y kinesiólogos - debían notificar de manera urgente, inmediata y forzosa a las autoridades sanitarias más cercanas, incluso si sólo tenían conocimiento por terceros o sospechas. Al realizar este movimiento, la viruela volvía a la palestra. Pasaba de ser una enfermedad olvidada, con brotes que obligaban a una acción en el momento para luego caer en la indiferencia, a una enfermedad preocupante. Da cuenta de este interés gubernamental que los datos sobre posibles contagios debían elevarse de inmediato desde cualquier punto del país y antes incluso de tener certeza a través de exámenes de laboratorio, lo cual difiere de las enfermedades del Grupo B y C que los requerían para las denuncias ${ }^{37}$.

En 1958, momento en el cual se reinició desde organismos internacionales el plan para erradicación de la viruela, el país había ingresado en una fase de expansión de la investigación científica y de creación institucional de organismos vinculados con la ciencia y la producción sin precedentes, coartada por el golpe militar de 1962 (CAMPINS; PFEIFFER, 2017). El Instituto Malbrán, que como hemos indicado es una nueva denominación de una institución ya existente, se refundó bajo este concepto de desarrollo científico con proyectos de biomedicina orientados a la investigación genética. Se contrató a figuras de renombre científico como Ignacio Pirosky, se invirtió en equipamiento de punta y se fortaleció la formación con becarios que estudiaban en laboratorios de Gran Bretaña y Francia, que por entonces descollaban en ese nuevo campo ${ }^{38}$. El quiebre democrático de

(empresarios, agentes secretos, militares y fuerzas armadas u organismos diplomáticos) e integran a otros, en una amplia gama de actividades (culturales y sociales). Los asuntos sanitarios podrían ser parte de estas relaciones, considerando además que habían surgido con anterioridad a través de la OPS, entre otras agencias. ${ }^{36}$ SEXTA reunión de los Ministros de Salud de los países de la Cuenca del Plata. Boletín de la Oficina Sanitaria Panamericana, v. 66, n. 3, p. 258-262, 1969.

${ }^{37} \mathrm{La}$ información debía permitir localizar a las personas y la fuente de infección. Debía indicar fecha, origen probable del foco y trasmitirse de manera urgente al Ministerio o a la Asistencia Pública, quien a su vez tenía que asistir, aislar al paciente y disponer sobre los cadáveres. La multa era de entre 500 a $10.000 \$ \mathrm{~m} / \mathrm{n}$, una fuerte suma por entonces, e incluía la suspensión del ejercicio profesional (LEY n. 15.465, 1960).

${ }^{38}$ Sobre este investigador, ver Kreimer y Ferpozzi (2016). 
1962 detuvo este crecimiento y partir de entonces, el Instituto viró a la actividad anterior, de corte "sanitarista", imbuida en el control epidemiológico y eje tradicional de su accionar (KREIMER; FERPOZZI, 2016).

La legislación de declaración obligatoria de 1960 quedó vigente y es la que en el momento rige en el caso del covid-19. Al acercarnos a algunas de estas campañas realizadas en Santa Fé, provincia del Litoral argentino, se destacan por un lado, aplicaciones de vacunas con el "purísimo suero provisto por el Instituto de Microbiología" (es decir, el Malbrán), refrigeradas para evitar justamente su deterioro (con la aplicación a domicilio, 1960, s/p) ${ }^{39}$. Por otro lado, se trata de campańas a domicilio de cobertura provincial con una clara intervención comunitaria, en este interludio de gobierno democrático. Se menciona así en la ciudad capital, de 208.900 habitantes, la organización de 52 brigadas, con la colaboración de gremios, corporaciones y centros de estudiantes y el uso de cámaras refrigeradas de comercios, colegios y particulares. Se vacunó a toda la población de la ciudad, controlando además si no era efectiva para revacunar días después, y allí, expender un certificado. Esta campańa, profusamente cubierta por la prensa, se realizaba entonces a nivel provincial, pero con material provisto por la nación y siguiendo la normativa de la OMS (Con la aplicación a domicilio, 1960). La provincia era una de las tres más pobladas del país, con un total de 1.884.918 habitantes (Censo Nacional, 1960).

Los esfuerzos de Argentina respecto a la erradicación de la viruela se enraizaron en la realización de campañas de vacunación masiva a raíz de una también expansión de la producción de antivariólica, hecho que se produjo sobre todo a partir de 1967. A diferencia de casi la totalidad de cepas recomendadas por la OPS y la OMS, el país vacunó con otra. Hasta 1967, a pesar de las indicaciones internacionales de utilizar la liofilización, se siguió usando la técnica de glicerinización descriptas desde principios del siglo. En el estudio minucioso de los informes de las diferentes naciones que participaron del programa de erradicación, se detecta que a pesar de que la OMS y la OPS inicialmente pidieron que solo se dispusiera de vacuna liofilizada, el gobierno argentino negoció el despliegue de la glicerinada, más económica y al menos durante la primera etapa, hasta el programa de intensificación (BHATTACHARYA; ÁVILA PEREIRA CAMPANI, 2019).

Las declaratorias de 1958 sobre la erradicación de la enfermedad no llegaron a plasmarse en acciones concretas hasta 1967, cuando la OMS requirió de los países miembros aportes monetarios en un Fondo especial para acelerar el proceso. En el caso argentino, las sumas irrisorias hacen pensar en una atención muy limitada: mientras Estados Unidos aportó 26.241.403 U\$, Argentina contribuyó con la modesta suma de sólo 13.275 U\$. Esa diferencia puede deberse a que la potencia mundial era también uno de los miembros del Consejo de Seguridad y factótum de esta política pero si comparamos con otras naciones

\footnotetext{
${ }^{39}$ Como señalamos, nuestro interés por campañas específicas de vacunación en algunas provincias seleccionadas obedece a una historización específica del proceso.
} 
latinoamericanas, la diferencia sigue siendo importante ya que Brasil aportó 128.925 U\$ en el mismo período, situación que obedecería a una intención mayor de este país por fortalecer la vacunación a través de las reglas internacionales y a que se trataba en la nación con mayor número de casos de América del Sur (L'ERADICATION, 1980; CUETO; PALMER, 2015).

Entre 1967 y 1980 se llevó adelante el programa de intensificación, que incluyó además novedosos estudios genéticos sobre los Orthopoxvirus para observar las posibilidades de reservorio animal naturales y prever futuros contagios ${ }^{40}$. Además se prestó especial atención a la calidad de la vacuna a través de una encuesta realizada a 77 laboratorios de 52 países; las respuestas recibidas se estabularon por continentes y no por naciones, razón por la cual no aparecen las de Argentina de manera individual. Sólo sabemos que efectivamente el laboratorio respondió a diferencia de otros en América Latina que no lo hicieron (como Bolivia, Ecuador y Perú), sobre la producción, conservación, distribución y otros aspectos técnicos de las vacunas (FENNER; HENDERSON; ARITA; JEZEK; LADNYI, 1988, p. 544).

La OPS y la OMS debían certificar los lotes de vacunas porque sobre todo en América del Sur, Africa y amplias regiones de Asia, el problema era la calidad de la producción. En el caso Argentino, como vimos, un solo laboratorio las producía y el control quedó a cargo del Connaugth Laboratories en Canadá para testear el potencial vírico, la estabilidad y el grado de contaminación bacteriana. En seminarios y reuniones realizadas por expertos, como el de 1968 realizado en Estados Unidos, participaron miembros de la OPS y de la OMS (Canadá, Estados Unidos, Gran Bretaña y la URSS) pero ninguno de Africa, de otros países de Asia o América del Sur. Se indicaron formas específicas de producción de vacunas, cómo mantenerlas en condiciones con equipos de refrigeración y la forma más eficaz de reconstituirlas en el momento de vacunar (FENNER; HENDERSON; ARITA; JEZEK; LADNYI, 1988; RODRIGUES, 1975). Los profesionales argentinos, como otros de toda América, recibieron la capacitación de los expertos y se familiarizaron con los procedimientos más innovadores pero no los lideraron en ninguna de sus fases.

Las evaluaciones de los lotes enviados por Argentina fueron considerados "satisfactorios" y se donaron vacunas para contribuir a la campaña de intensificación (810.000 dosis), asimilándose en esto a otras como Perú y Brasil de América del Sur (FENNER; HENDERSON; ARITA; JEZEK; LADNYI, 1988, p. 560; 564).

Hasta 1967, se utilizaron las lancetas, la vaccinostyle o simplemente una aguja; una gran modificación se produjo en 1969 con el uso de la aguja bifurcada, recomendada por la ONU para lograr más eficacia en el momento de vacunar y ahorrar dosis. Se observa una diferencia en las cepas para la producción liofilizada, ya que en el caso argentino se utilizó en 1968 de la cepa Massachusetts 999, mientras que en 1971 y seguramente bajo la

\footnotetext{
${ }^{40}$ En el estudio de ADN viral a través de test serológicos se compararon los diversos tipos de Orthopoxvirus (Mokeypox, Teterapox, Variola major, Alastrim, Vaccinia Lister y Vaccinia Venezuela) en Fenner, Henderson, Arita, Jezek y Ladnyi (1988, p. 94).
} 
recomendación internacional se utilizó la cepa Lister (FENNER; HENDERSON; ARITA; JEZEK; LADNYI, 1988, p. 584). Hubo estudios también que recomendaban el uso de un sistema novedoso con “jet injector" 11.

Una cuestión que da cuenta de que las políticas de erradicación de la viruela en estos momentos no eran el principal problema para la nación argentina lo demuestra el número de casos detectados. Entre 1959 y 1971, hubo en total 211 casos, pero años enteros no se presentaron contagios $(1963,1968,1971)$, y otros (1967) se trató de enfermos que venían de regiones cercanas. Dada la frontera porosa que existía con países vecinos, los casos siguieron existiendo a uno y otro lado, por ejemplo, en 1970 un contagio detectado en Río Grande Do Sul de una joven proveniente de Colonia Alicia (Provincia de Misiones, en Argentina) forzó a vacunar o re-vacunar al 84 \% de la población provincial (RODRIGUES, 1975).

Si se compara con países donde el endemismo persistía, como Brasil, Colombia y Ecuador, se advierte una diferencia significativa respecto a la situación epidemiológica, porque no se trataba ya de una enfermedad sin control. Pero dados los compromisos internacionales, las políticas debieron realizarse con presupuesto nacional, dado que Argentina recibió cifras irrisorias tanto de la OMS como de la OPS para el programa; entre 1953-1971, 236.000 U\$, de un total de 1.124.000 U\$ y de los cuales, Brasil fue el mayor beneficiario (FENNER; HENDERSON; ARITA; JEZEK; LADNYI, 1988; sobre Brasil un examen detallado en CUETO; PALMER, 2015).

Pero a pesar de que se trató de una enfermedad con muy pocos casos, las acciones de vacunación fueron sin duda impactantes, de cobertura casi universal. Las campañas que se realizaron en la etapa de intensificación, entre 1967-1972, cubrieron prácticamente todo el territorio sudamericano. En el caso argentino, se abarcó casi toda el área nacional, ya que los programas de vacunación masiva sólo dejaron de lado las Provincias de Buenos Aires, parte de Entre Ríos y Neuquén.

Rodrigues, quien era el encargado de la OMS para América del Sur y Adviser on Small Pox Erradication, cita cientos de miles de vacunados anualmente en ese período, cuando Argentina tenía más de 23 millones de habitantes. Así, en 1967 se vacunaron a 1.808 .000 personas; un año después a 324.000; en 1969 a 2.141.000 y en 1970 la cifra ascendió a casi la mitad de la población: 11.009.000 vacunados (RODRIGUES, 1975). Las vacunas se produjeron, continuando con una tradición casi centenaria, en el país, con la nueva tecnología sugerida por los organismos internacionales, como el uso de cepas aceptadas y las agujas bifurcadas. Incluso tenemos evidencias de la utilización en la campaña provincial de La Pampa del "jet injector”².

\footnotetext{
${ }^{41}$ Ver una descripción del uso de este sistema mecánico que permitía un uso más eficaz de las dosis en Millar, Roberto, Wulff, Wenner y Henderson (1969).

42 "Vacunación antivariólica”, en Diario La Arena, 5 de noviembre de 1971. En la fotografía, se indica que en la campaña se utiliza este sistema, con el que se vacunó al entonces Ministro de Bienestar Social provincial. El uso de figuras públicas como funcionarios de alto nivel para lanzar una campańa sanitaria se utiliza como método publicitario para lograr aprobación social.
} 
El esfuerzo argentino fue notable; en 1967 se fabricaron 560.000; en 1968, 14.944.800; en 1969, 21.427.850; en 1970 la cifra se duplicó a 44.350.325 dosis; en 1971 se produjeron 12.218. 600; y un año después, en 1972, 17.456 .000 (FENNER; HENDERSON; ARITA; JEZEK; LADNYI, 1988 ${ }^{43}$. En algunas provincias, como La Pampa, sólo en el año 1971 se registraron 105.000 personas vacunadas, es decir, el $61 \%$ del total de la población provincial (TRAPAGLIA, 1973).

Luego del programa de intensificación, se aplicó el de vigilancia epidemiológica; en Argentina lo facilitó la existencia previa de la legislación ya citada ya que los casos considerados sospechosos fueron comunicados telefónicamente o por radiocomunicación de manera inmediata. En 1971, los consultores contratados por la OPS realizaron visitas a 14 localidades en las Provincias de Buenos Aires, Corrientes, Misiones y Santa Fé y desarrollaron 86 entrevistas, sin detectar contagios de viruela (RODRIGUES, 1975). En 1973, se realizaron nuevas campañas masivas, instando a la población a ejercer su derecho y a la vez, como deber comunitario, con vacunas liofilizadas más eficaces que permitían la conservación de virus vivos sin refrigeración, y en consecuencia, evitando los "vicios" de las glicerinadas ${ }^{44}$.

En base a la información anterior, y a la desaparición de casos de manera total en Argentina a partir de 1971, se declaró al país libre de viruela y bajo la recomendación de la Sociedad Argentina de Pediatría, se eliminó la vacunación antivariólica definitivamente en 1979, en plena dictadura militar, por los riesgos que suponía en los niños que tenían solo una remota posibilidad de enfermar (Ley no $22.109,1978-1979) .{ }^{45}$

\section{Conclusiones}

En 1980, frente al discurso exultante de erradicación, el director de la OMS afirmaba al mismo tiempo que ese organismo internacional no iba a continuar con la erradicación de otras enfermedades, cuando se desplegaba una nueva lógica entre salud y neoliberalismo. Tal cuestión nos permite preguntarnos sobre si era realmente imprescindible en la agenda de muchos Estados subdesarrollados o en vías de desarrollo esa prioridad, que dejó de lado la inversión en recursos humanos e infraestructura sanitaria quizás menos urgentes, pero

\footnotetext{
43 A manera de comparación, en el mismo período en Bolivia se produjeron cifras muy inferiores, para una población en condiciones similares (entre 400.000 y 235.250 dosis). Ese país también utilizó para el diagnóstico de la viruela, a finales de los años Sesenta, a laboratorios de Argentina y Brasil, y dejó de usar los centros existentes en América del Norte previstos por el programa (RODRIGUES, 1975).

${ }^{44}$ PROTEGERSE contra la viruela no es sólo un derecho sino un deber. El Litoral, Diario, 10 sep. 1973.

${ }^{45}$ Además, debieron influir las razones económicas que exponía Arita, uno de los especialistas de la OMS en 1980, indicando que "El cese de la vacunación no solo salvará a miles de pacientes que de otro modo habrían sufrido complicaciones frontales, sino también le ahorrará a la comunidad mundial unos \$1.000 millones al año" (ARITA, 1980, p. 27, mi traducción).
} 
más necesarias. Tanto Birn (2016) como Cueto e Palmer (2015) indican acertadamente esa situación que en el caso argentino también se sustenta dado que el control de la enfermedad se había logrado mucho antes, con una política extensiva de vacunación dirigida a un amplio conjunto social. Los brotes posteriores se corresponden con una enfermedad que había ingresado en un circuito de endemia controlada. Y si bien la tecnología básica de vacunación provino de experiencias fuera del país, Argentina aplicó tempranamente un sistema de producción propio y eficaz sin requerir apoyo de laboratorios privados o ayuda externa. Tales particularidades se verifican a principios de Siglo XX y fueron parte de la agenda de un sector médico profesional muy vinculado al Estado, se mantuvieron con ciertos altibajos pero sin retroceder hasta que se firmaron los acuerdos internacionales con OPS-OMS para la erradicación de la viruela.

En estos casi dos siglos, las variaciones respecto a la sociedad en su conjunto y también a las calificaciones científicas sobre la enfermedad alientan a reflexionar sobre algunos posibles aspectos. Una primera cuestión apunta a las características de la resistencia de la población en general, a la inoculación variólica desde principios hasta casi finales del Siglo XIX. Producto del traslado artificial de un virus a otra persona, y con alto riesgo de infección y contagio a su vez de otras enfermedades, se la consideraba como la única medida efectiva por un colectivo profesional amplio pero sin impacto total en el sistema político. Como indicamos (DI LISCIA, 2011), se utilizó a personas sin protección - menores, etnias cautivas -, tanto como reservorio para vacunar "brazo a brazo" con vacuna humanizada como para activar otros mecanismos no exactamente médicos. Las alianzas y su contrario, la eliminación en tiempos de guerra también se tejieron administrando o negando esta posibilidad si bien riesgosa, pero la única con ciertas perspectivas de éxito. Pero aún con el uso del Cow Pox, era una práctica artesanal, de escaso control público y por lo tanto, abierta a muchas y posibles digresiones del canon científico establecido. En la defensa de la inoculación y luego de la vacunación de los médicos del S. XIX se percibe una incertidumbre y a la vez, pocas perspectivas de transformar una sociedad que, en su conjunto, no recibe con total beneplácito estas ventajas. A partir de la influencia y presión de una comunidad médica cohesionada y con incidencia estatal, la persistencia de la enfermedad se analizó como parte del atraso general del país y de la ignorancia de la población. Este fenómeno vino unido a epidemias recurrentes, y todos esos factores impulsaron la obligatoriedad de la vacunación antivariólica.

En segundo lugar, hacia 1904 se abre otro período, donde la medida se sanciona por Ley para una parte del país de manera obligatoria que luego se extiende a todas las jurisdicciones provinciales. La vacunación con Cow Pox pierde esa denominación y se transforma en antivariólica a secas, se organiza de manera centralizada, a través del DNH y de una institución vinculada a éste, el Instituto Bacteriológico. Es realmente una de las pocas prácticas sanitarias sostenidas hasta su eliminación en 1979, y su persistencia atraviesa cambios de los mismos organismos sanitarios, que pasan a constituir secretarías, ministerios 
y a variar en su composición y alcances. El sistema establecido involucraba un circuito amplio de producción que incluía un sector veterinario (de varios cientos de terneras al año), técnicos para extraer y manipular la linfa con glicerina en placas de vidrio y luego, otro de distribución. Primero se realizaba a través del correo, y luego, para acelerar la eficacia y permitir la aplicación efectiva, de agentes vacunadores desplegados en principio sólo por los Territorios Nacionales y la Capital Federal. Estas campañas tan iniciales, que se corresponden con la primera década del Siglo XX y que hemos denominado "prácticas itinerantes", proporcionan al Estado también otras posibilidades, paralelas a la medicalización, como el conocimiento y apropiación de los territorios y de su población, la mayoría recién llegada de otros países y regiones. Los recursos eran mucho más importantes que en anteriores épocas y provenían no sólo de una economía en expansión sino de signos halagüeños de los sectores políticos. La vacunación era así el brazo civilizador (real) y sanitario del Estado en espacios recién conquistados, arrebatados a las etnias originarias, donde se intentaba implantar población inmigrante de Ultramar.

Las agencias educativas nacionales compartieron la preocupación por la vacunación y constituyeron un aspecto clave en la desaparición de los estigmas populares que la rodeaban. Con la alfabetización, también se amplió la vacunación inicialmente contra la viruela y luego contra otras enfermedades, como la difteria y la polio e incluso la demarcación entre enfermedad y certificación burocrática, que cerraba el ciclo del control. La conexión higieneeducación no eliminó ciertamente las nociones de la enfermedad bajo sus aspectos estéticos, supuestamente de mayor impacto entre las mujeres: de acuerdo al ideal de género debían mantener la belleza para acceder al matrimonio. Se trata de un tema interesante a explorar en relación a otras patologías cuya peligrosidad sin duda era mayor pero que no ocasionaban ni las pústulas supurantes o dejaban señas identificatorias en la piel.

En los años Veinte y Treinta, se consolidó la fabricación de la antivariólica de manera totalmente exclusiva en el sistema público. La industria farmacéutica, que se expandió por las potencialidades tanto del mercado argentino (consumidor de medicamentos, gracias a una floreciente clase media), de la particular situación externa por el cierre de importaciones como de los ajustes políticos, no tuvo acceso a la producción de estas vacunas. El Estado las producía y distribuía gratuitamente para estimular la vacunación, en cientos de miles de dosis por año. La estandarización del proceso técnico permitió ampliar la cantidad y reemplazar placas por tubos, en una tarea rutinaria y que sin embargo, no alcanzaba a eliminar la enfermedad, al requerir permanente re-actualización. El sistema hacía agua justamente al no haberse impulsado su innovación.

La viruela se controló pero no desapareció totalmente; se transformó en una enfermedad endémica con brotes cada ocho, diez o doce años; hubo noticias de casos en 1923, 1935 a 1937 y 1949-1950 en diferentes provincias que obligaron a, nuevamente, vacunar, de acuerdo a lo que hemos indicado con anterioridad. En esos momentos, se criticaba la 
escasez de producto en algunas áreas o su calidad defectuosa en otras, alentando a mejorar los aspectos técnicos. Aparentemente, no hubo resistencia organizada de algún sector; al momento, no encontramos movimientos en contra de una medida que, al ser obligatoria, debía introducirse sin discusión en todos los individuos para ser efectiva, tal y como se aseguraba en las publicaciones sanitarias sin distinción.

Es por ello que se aceptó el programa de erradicación; Argentina lo implementó con una nueva legislación de obligatoriedad de declaración de enfermedades en 1960, que implicaba sanciones graves para la corporación de profesionales de salud si no se informaban casos sospechosos en tiempo y forma. La viruela adquirió así una nueva entidad: de enfermedad casi olvidada que volvía periódicamente para recordarles sobre todo a los decisores de políticas públicas su existencia, se transformó en una posible causa para devolver a la Nación cierta relevancia en el concierto internacional. Recordemos que los profesionales de Argentina, a diferencia de Brasil, no tuvieron directa participación en las decisiones de la OMS ni tampoco, salvo en general como participantes en seminarios de capacitación, en la OPS en relación con la erradicación. En el caso de las campañas, diferentes sectores abrazaron la "causa" de la erradicación, sin que puedan detectarse conflictos a pesar de que el proceso estuvo en medio de bruscos cambios políticos e intervinieron aquí tanto regímenes democráticos como aquellos surgidos de quiebres institucionales y golpes militares.

Llaman entonces poderosamente la atención estos acuerdos en pos de la erradicación de la viruela, dado que en otros aspectos no los había en absoluto. Por ejemplo, en relación a la atención médica y al suministro de medicamentos, que involucraban a gremios y poderosas corporaciones médico-farmacéuticas y al Estado, hay evidencias de que las empresas farmacéuticas hicieron lobby para apoyar a sectores contrarios a los gobiernos institucionales de turno (ROMÁN, 2020). Y que no hubo posibilidad, desde mediados del siglo XX, para gestar un sistema unificado de salud por la intensa acción contraria de sectores privados, gremios y corporaciones de profesionales.

En esta situación, Argentina logró entonces insertarse en el concierto internacional con una medida muy publicitada y de corte humanitario, que finalizó exitosamente "matando" a una enfermedad (Smallpox is dead, el lema de 1980). En las convulsiones de la Guerra Fría y luego, con las demandas crecientes del Tercer Mundo, eliminar de cuajo una enfermedad proporcionaba alicientes sobre otros posibles acuerdos que finalmente no llegaron, para también lograr lo mismo con la pobreza o la desigualdad. En este camino, trazado sobre la paz y en pos del acuerdo de naciones muy diversas, la OPS dirigió la campaña de América del Sur y allí se denotan ciertas renuencias de Argentina al menos en aspectos técnicos.

El país recibió escasos recursos para el programa; tampoco Argentina fue un entusiasta financista ya que sus aportes fueron muy exiguos. Una de las principales campañas realizadas en 1960 a nivel provincial, menciona los aspectos "nacionales" y sólo a la OMS para indicar sus valoraciones respecto al tipo de práctica de inmunización. Se utilizaron vacunas glicerinadas, 
a pesar de que no eran las recomendadas. Y además, las cepas virales no eran las utilizadas en otras regiones, ¿producto de un desarrollo especial del país o de una especie de atrofia del laboratorio? El Instituto a cargo de esta tarea, que llevaba varias décadas produciendo las vacunas, se modernizó e introdujo otros aspectos de investigación biotecnológica a finales de los Cincuenta pero luego, a partir de políticas tanto de gobiernos autoritarios como de una elección rutinaria, se volvió a actividades previas de corte sanitarista. En estas evidencias estaría quizás la clave de interpretación de cómo el proceso de producción de vacunas permitía hablar de millones de dosis, incluso incrementadas año a año, con sistemas ya obsoletos. El material resultante aumentaba en cantidad, para cubrir a los 20 millones de argentinos que por entonces eran la población total, pero no así en calidad, dado que se debía revacunar periódicamente como antaño. Hasta los ańos Setenta no se utilizaron las vacunas liofilizadas, más estables, y quizás el apoyo presupuestario de la OMS está en la base de esa reconversión técnica significativa.

¿En qué momento se controló la viruela? Si nos atenemos a la información demográfica, esta enfermedad infecciosa dejó de ser una preocupación sanitaria hacia 1920; los brotes posteriores se circunscribían a determinadas localidades limítrofes o con puertos y a trabajadores migrantes. En los años Sesenta y Setenta, el esfuerzo en la erradicación, con la vacunación o revacunación de millones de personas, iba de la mano del impacto mediático nacional. Aún en momentos de convulsiones políticas era una medida aceptada sin disturbios y con acuerdos de la comunidad en su conjunta. Quizás sería preciso analizarla también a nivel del subcontinente en pos de acuerdos políticos mayores, como aquellos logrados por Estados Unidos para la lucha anticomunista.

La vacunación antivariólica impactó también de manera general en lo que llamamos, grosso modo, “medicalización”, dado que las primeras campañas representaban para muchos habitantes la a veces única presencia material y efectiva del Estado, confusa entidad poco presente en otros momentos. A la vez, con las vacunas llegaban otros profesionales y medidas de saneamiento o desinfección de mayor impacto, por ejemplo, para la revisión de los niños y trabajadores con problemas de salud graves o potenciales. En 1977, se creó a nivel internacional el Programa Ampliado de Inmunización (PAI), que la Argentina integró desde 1978 con cuatro vacunas y amplió progresivamente para llegar al presente con un calendario mucho más profuso ${ }^{46}$. Cuando se eliminó la viruela ya estaba presente un nuevo calendario de vacunación para el sarampión y la poliomelitis por lo cual podía reutilizarse el sistema de vigilancia epidemiológica ensayado con la viruela (RODRIGUES, 1975). Posteriormente, se dieron indicaciones de destruir las existencias de virus dado que la enfermedad tampoco era pasible de reproducirse ni contagiarse por ningún medio (animales o persona a persona)

\footnotetext{
${ }^{46}$ En 1997 se incorpora la vacuna triple viral (contra el sarampión, la rubeola y la paperas); en 1998 la vacuna conjugada Haemophilus influenzae tipo b (incluida en la cuádruple), en el 2000 la vacuna contra la hepatitis B (HB) y en el 2005 la vacuna contra la hepatitis A. En 2012, el país incluía 16 vacunas (VACUNAS, 2012).
} 
y la OMS controló a los laboratorios que disponían de reservorios de manera sistemática ${ }^{47}$. Este punto final, si lo es, da cuenta de la complejidad de las enfermedades de alto contagio y dispersión, cuando se solapan con otros y variados usos, siempre políticos.

\section{Fuentes}

ARGENTINA. Boletín de la Oficina Sanitaria Panamericana, v. 18, n. 8, p. 875-879, 1939. CENSO Nacional de Población. Tomo IV. Zona Central. Córdoba-Santa Fé, 1960.

CIRCULAR del Ministerio del Interior solicitando de los gobiernos provinciales el envío de datos estadísticos. Anales del Departamento Nacional de Higiene, año XV, n. 6, p. 318-319, 1908.

CON LA aplicación a domicilio de vacunas, empezó la campaña provincial de acción contra la viruela. El Litoral, Diario, 27 oct. 1960.

EPIDEMIA de viruela. El Orden, Diario, 27 oct. 1935.

EPIDEMIA de viruela. Santa Fé, Diario, 10 feb. 1923.

ÉRADICATION de la variole: destruction des stocks de virus variolique. Rapport $d u$ Secrétariat. Géneve: OMS, 2011.

LERADICATION Mondiale de la Variole. Rapport final de la Comission Mondiale pour la Certification de la Eradication de la Variole. Genève: OMS, 1980.

LA SANIDAD en Argentina. Boletín de la Oficina Sanitaria Panamericana, v. 16, n. 6, p. 509-522, 1937.

LA VIRUELA en las Américas. Oficina Sanitaria Panamericana, año 2, n. 304, 1924.

LEY de Salud Pública n. 15.465. Honorable Congreso de la Nación, 28 oct. 1960. Disponible en: http://servicios.infoleg.gob.ar/infolegInternet/anexos/195000-199999/195289/norma. htm. Acceso en: 20 jun. 2020.

LEY n. 22.109, de 22 de noviembre de 1978, Sanción: 22 nov. 1979; Promulgación: 22 nov. 1979. Poder Ejecutivo Nacional. Buenos Aires. Boletin Oficial 1979; 30 nov. Disponible en: http://servicios.infoleg.gob.ar/infolegInternet/anexos/230000-234999/231268/norma. htm. Acceso en: 20 dec. 2020.

PROGRESOS realizados en higiene e informes sanitarios. Boletín de la Organización Panamericana de la Salud, v. 7, n. 1, p. 273-280, 1928.

PELIGRO de epidemia de viruela. El Litoral, Diario, 5 jul. 1957.

PROTEGERSE contra la viruela no es sólo un derecho sino un deber. El Litoral, Diario, 10

\footnotetext{
${ }^{47}$ ÉRADICATION de la variole, 2011.
} 
sep. 1973.

SEXTA reunión de los Ministros de Salud de los países de la Cuenca del Plata. Boletín de la Oficina Sanitaria Panamericana, v. 66, n. 3, p. 258-262, 1969.

SMALL Pox is dead. World Health, The Magazine Of The World Health Organization, Geneva, p. $1-40,1980$.

VACUNAS: el derecho a la prevención. Buenos Aires: Ministerio de Educación de la Nación y Ministerio de Salud de la Nación, 2012.

VACUNACIÓN antivariólica. Diario La Arena, 5 nov. 1971.

VIRUELA. Boletín de la Oficina Sanitaria Panamericana, v. 10, n. 10, p. 1.328-1.331, 1931.

VIRUELA. Boletín de la Oficina Sanitaria Panamericana, v. 15, n. 7, p. 679-685, 1936.

VIRUELA. Boletín de la Oficina Sanitaria Panamericana, v. 16, n. 8, p. 760-771, 1937.

VIRUELA. El Litoral, Diario, 17 nov. 1950.

\section{Referencias}

ALVAREZ, Adriana Carlina. Malaria and the Emergence of Rural Health in Argentina: an Analysis for the Perspective of International Interaction and Cooperation. Canadian Bulletin of Medical History, v. 25, n. 1, p. 137-160, 2004.

ALVAREZ, Fernando. La viruela y la vacuna en la República Argentina. El Monitor de la Educación Común, año 35, n. 530, p. 101-105, 1917.

AMORETTI, Alejandro. Vacuna e inoculación vaccínica. Tesis Inaugural. Buenos Aires: Imprenta de M. Viedma, 1886.

ARMUS, Diego. The Ailing City. Health, Tuberculosis and Culture in Buenos Aires, 18701950. Durham and London: Duke University Press, 2011.

ARITA, Isao. Can we stop smallpox vaccination? World Health, The Magazine Of The World Health Organization, Geneva, p. 27-29, 1980.

BARON DE FINCK, Carlos. Disertación de la viruela y su tratamiento. Tesis (Doctorado en Medicina), Facultad de Ciencias Médicas de Buenos Aires, 1855.

BELMARTINO, Susana. La atención médica argentina en el Siglo XX. Buenos Aires: Sudamericana, 2005.

BENCHIMOL, Jaime. Yellow fever vaccine in Brazil: fighting a tropical scourge, modernising the Nation. In: HOLMBERG, Christine; BLUME, Stuart; GREENOUGH, Paul (eds.). The politics of vaccination. A global history. Manchester: Manchester University Press, 2017. p. 174-208. 
BIERNAT, Carolina. El proceso de centralización del Departamento Nacional de Higiene (1880-1914). In: BIERNAT, Carolina; CERDÁ, Juan Manuel; RAMACCIOTTI, Karina Inés (dir). La salud pública y la enfermería en Argentina. Buenos Aires. UNQUI, 2015. p. 47-83.

BHATTACHARYA, Sanjoy; ÁVILA PEREIRA CAMPANI, Carlos Eduardo. Reassessing the foundations: worldwide smallpox eradication, 1957-1967. Medical History, v. 71, n. 93, 2019.

BIRN, Anne-Emanuelle. Sueños y pesadillas de la erradicación de la viruela: reflexiones críticas para la salud global. In: PORRAS GALLO, María Isabel; BÁGUENA CERVELLERA, María José; AYARZAGÜENA SANZ, Mariano; MARTÍN ESPINOSA, Noelia María (coords.). La erradicación y el control de las enfermedades infecciosas. Madrid: Catarata, 2016. p. 39-49.

BIRN, Anne-Emanuelle. How to have narrative-flipping history in a pandemic: views of/ from Latin America. Centaurus, v. 62, p. 354-369, 2020.

BRAMUGLIA, Cristina; ABRUTZKY, Rosana; GODIO, Cristina. Análisis de la industria farmacéutica estatal en Argentina. Documentos de Jóvenes Investigadores, Buenos Aires, n. 34, Instituto de Investigaciones Gino Germani, 2012.

CALANDRA, Benedetta; FRANCO, Marina. Desafíos y límites para una nueva mirada de las relaciones interamericanas. In: CALANDRA, Benedetta; FRANCO, Marina (eds.). La guerra fría cultural en América Latina. Desafios y límites para una nueva mirada de las relaciones interamericanas. Buenos Aires: Biblios, 2012. p. 35-50.

CAMPINS, Mónica; PFEIFFER, Ana. La industria farmacéutica argentina y su entorno socio-económico (1958-2010). Anuario CEEED, año 9, p. 91-133, 2017.

CAPONI, Sandra. Miasmas, microbios y conventillos. Asclepio. Revista de Historia de la Medicina y de la Ciencias, v. LIV, n. 1, p. 155-181, 2002.

CARRILLO, Ana María. Vaccine production, national security anxieties and the unstable state in nineteenth and twentieth-century Mexico. In: HOLMBERG, Christine; BLUME, Stuart; GREENOUGH, Paul (eds.). The politics of vaccination. A global history. Manchester: Manchester University Press, 2017. p. 121-147.

CARRILlO, Ramón. Política sanitaria argentina. Buenos Aires: Ministerio de Salud de la Nación, 1949.

CONI, Emilio. Contribución al estudio de la viruela en la Provincia de Buenos Aires. Memoria presentada a la Asociación Médica Bonaerense. Buenos Aires: Imprenta Pablo E. Coni, 1878.

CONI, Emilio. Apuntes sobre el movimiento de la población en la ciudad de Buenos Aires durante el año 1878. Buenos Aires: Imprenta Pablo E. Coni, 1879. 
CONI, Emilio. La viruela en Buenos Aires. La Semana Médica, año XXIV, n. 49, p. 629, 1917.

CONRAD, Peter; BAKER, Kristin. The social construction of Illness: Key Insights and Policy Implications. Journal of Health and Social Behavior, v. 51, n. S, p. 567-579, 2010.

CUETO, Marcos; PALMER, Steven. Medicine and Public Health in Latin America: a History. New York: Cambridge University Press, 2015.

DI LISCIA, María Silvia. Médicos y maestros. Higiene, eugenesia y educación en Argentina, 1880-1940. In: DI LISCIA, María Silvia; SALTO, Graciela Nélida (eds.). Higienismo, educación y discurso en la Argentina, 1870-1940. Santa Rosa: EDULPAM, 2004. p. 37-64.

DI LISCIA, María Silvia. Instituciones “portátiles”. La sanidad pública en los Territorios Nacionales (1880-1910). In: SOPRANO, Germán; BOHOSLAVSKY, Ernesto. Un Estado con rostro humano. Funcionarios e instituciones estatales en Argentina (de 1880 a la actualidad). Buenos Aires: Prometeo-UNGS, 2010. p. 359-385.

DI LISCIA, María Silvia. Marcados en la piel: vacunación y viruela en Argentina (18701910). Ciência \& Saúde Colectiva, v. 16, n. 2, p. 409-422, 2011.

DI LISCIA, María Silvia. Del brazo civilizador a la defensa nacional: Políticas sanitarias, atención médica y población rural (Argentina, 1900-1930). Historia Caribe, Universidad del Atlántico, v. 12, n. 31, 2017.

DI LISCIA, María Silvia. Perfiles y trayectorias: los agentes sanitarios frente a la inspección de inmigrantes (Argentina, 1876-1933). In: SOPRANO, Germán; RODRÍGUEZ, Laura Graciela (eds.). Profesionales e intelectuales de Estado. Análisis de perfiles y trayectorias en la salud pública, la educación y las Fuerzas. Rosario: Prohistoria, 2018. p. 95-119.

DÍAZ, Juan José. Profilaxis de la viruela. Tesis (Doctorado en Medicina), Facultad de Ciencias Médicas. Buenos Aires: Imprenta Pablo Coni, 1876.

DURBACH, Nadja. Bodily Matters: the Anti-Vaccination Movement in England, 18531907. Durham and London: Duke University Press, 2005.

ESPINOSA, Mariola. Globalizing the History of Disease, Medicine, and Public Health in Latin America. Isis, v. 104, n. 4, p. 798-806, 2013.

FENNER, Frank; HENDERSON, Donald A.; ARITA, Isao; JEZEK, Zdenek; LADNYI, Iván D. Smallpox and Its Erradication. Genève: Word Health Organization, 1988.

GONZÁLEZ LEANDRI, Ricardo. Curar, persuadir, gobernar: la construcción histórica de la profesión médica en Buenos Aires, 1852-1886. Madrid: CSIC, 1999.

GRUSHKA, Carlos. Casi un siglo y medio de mortalidad en la Argentina. Revista Latinoamericana de Población, año 8, n. 15, p. 93-118, 2014.

HANSEN, Julio. Vacunación antivariólica. Revista de Educación Sanitaria, año II, n. 5-6, p. 8-10, 1954. 
HOCHMAN, Gilberto. Vacinação, varíola e uma cultura da imunização no Brasil. Ciência \& Saúde Colectiva, v. 16, n. 2, p. 375-386, 2011.

HOLMBERG, Christine; BLUME, Stuart; GREENOUGH, Paul (eds.). The politics of vaccination. A global history. Manchester: Manchester University Press, 2017.

KREIMER, Pablo; Hugo, FERPOZZI. De Milstein a la bioinformática. Emergencia y desarrollo de la biología molecular en Argentina. In: KREIMER, Pablo (eds.). Contra viento y marea. Emergencia y desarrollo de campos cientificos en la periferia, Argentina, segunda mitad del Siglo XX. Buenos Aires: CLACSO, 2016. p. 105-145.

LARGUÍA, Alfredo. La vacuna en la República Argentina. Tesis. Buenos Aires: Imprenta y Casa Editora de Agustín Etchepareborda, 1901.

LEDESMA, Justiniano. Consideraciones sugeridas con motivo a los proyectos de vacunación obligatoria. Revista Médico Quirúrgica, n. 15, p. 403-404, 1878.

LOZANO, Nicolás. Memoria de la Sección 1era (Profilaxis interna y de vacuna), correspondiente al año 1907. Anales del Departamento Nacional de Higiene, año XV, n. 6, p. 243-257, 1908.

McNEILL, William. Plagues and peoples. New York: Anchor Press, 1976.

MILLAR, Donald; ROBERTO, Ronald; WULFF, Herta; WENNER, Herbert; HENDERSON, D. A. Smallpox Vaccination by Intradermal Jet Injection. Bulletin de la Organisation Mondiale de la Santé-Bulletin of Word Health Organisation, n. 41, p. 749-760, 1969.

MOUliN, Anne Marie. Prémières vaccines, premières réticenses. Pour la Science, n. 264, p. $13-15,1999$.

MOULIN, Anne Marie. Les déterminants de la politique vaccinale. ADSP, n. 71, juin, p. 14-16, 2010.

OTERO, Hernán. Estadistica y nación. Una historia conceptual del pensamiento censal de la Argentina moderna, 1869-1914. Buenos Aires: Prometeo Libros, 2006.

PORRAS GALLO, María Isabel; BALLESTER AÑÓN, Rosa. Luces y sombras de la erradicación de las enfermedades infecciosas: interés historiográfico y reflexión para la salud pública actual. In: PORRAS GALLO, María Isabel; BÁGUENA CERVELLERA, María José; AYARZAGÜENA SANZ, Mariano; MARTÍN ESPINOSA, Noelia María (coords.). La erradicación y el control de las enfermedades infecciosas. Madrid: Catarata, 2016. p. 19-38. PENNA, José. La viruela en la América del Sud y principalmente en la República Argentina. Historia, estadistica, clinica y profilaxia. Buenos Aires: Félix Lajuane ed., 1885.

PENNA, José; MADERO, Horacio. La administración sanitaria y la asistencia pública de la ciudad de Buenos Aires. Tomo II. Buenos Aires: Imprenta, Litografía y Encuadernación G. Kraft, 1910. 
PENNA, José; RESTAGNIO, Antonio. Atlas sanitario argentino (contribuciones para su estudio). Buenos Aires: Ministerio del Interior, 1916.

RAMACCIOTTI, Karina Inés. Hospitales públicos y campañas sanitarias, (1945-1955). In: BIERNAT, Carolina; CERDÁ, Juan Manuel; RAMACCIOTTI, Karina Inés (dirs.). La salud pública y la enfermería en Argentina. Buenos Aires: UNQUI, 2015. p. 123-168.

RILEY, James C. Smallpox and American Indians Revisited. Journal of The History of Medicine and Allied Sciences, v. 65, n. 4, p. 445-477, 2010.

RODRÍGUES, Bichat. Small Pox Erradication. Bulletin Panamerican Health Organisation, v. 9, n. 1, 1975.

ROMÁN, Viviana. El sector farmacoquímico en la Argentina. Orígenes, desarrollo y acción estatal. In: ROMÁN, Viviana; SALAS, Ernesto. Arturo Ońativia y la Ley de Medicamentos. Cuadernos del Instituto de Salud, Florencio Varela, UNAJ, n. 4, p. 11-28, 2020.

SUSSINI, Miguel. La sanidad en Argentina. Boletín de la Oficina Sanitaria Panamericana, v. 18, n. 6, p. 509-515, 1939.

TEDESCO, Juan Carlos; CARDINI, Alejandra. Educación y sociedad: proyectos educativos y perspectivas futuras. In: TORRADO, Susana (comp.). Población y bienestar en la Argentina del primero al segundo Centenario. Una historia social del Siglo XX. Tomo II. Buenos Aires: EDHASA, 2007. p. 439-467.

TRAPAGLIA, Angel Benjamín. Dos años de Gobierno en La Pampa, 1971-1973. Santa Rosa: Consejo Provincial de Difusión, 1973.

VERONELLI, Juan Carlos; VERONELLI CORRECH, Magalí. Los orígenes de la salud pública en Argentina, Tomo II. Buenos Aires: Organización Panamericana de la Salud, 2004. WATTS, Sheldon. Epidemics and history: disease, power and imperialism. New Haven: Yale University Press, 1999.

WEBB JR, James. Historical epidemiology and global health history. História, Ciências, Saúde - Manguinhos, Rio de Janeiro, v. 27, supl., set. p. 13-28, 2020. 